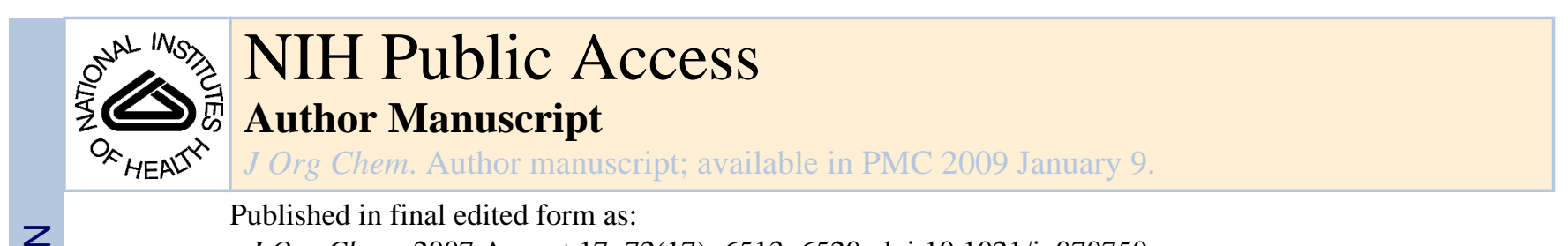

Published in final edited form as:

J Org Chem. 2007 August 17; 72(17): 6513-6520. doi:10.1021/jo070750s.

\title{
Synthesis of the antigenic tetrasaccharide side chain from the major glycoprotein of Bacillus anthracis exosporium
}

\author{
David Crich and Olga Vinogradova \\ Department of Chemistry, University of Illinois at Chicago, 845 West Taylor Street, Chicago, Illinois \\ 60607-7061,dcrich@uic.edu
}

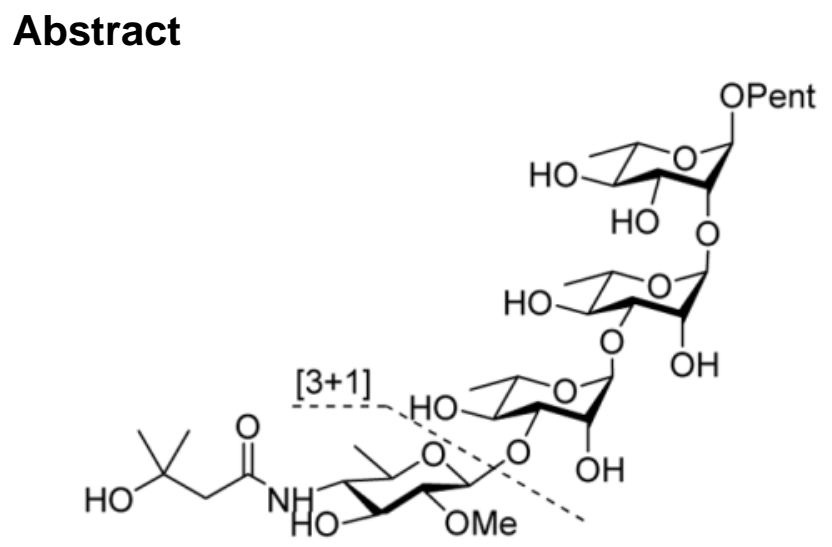

A synthesis of the pententyl glycoside of the tetrasaccharide side chain from the major glycoprotein of Bacillus anthracis by a [3+1] approach is described. The construction of the 1,2-trans-glycosidic linkage in the terminal anthrose moiety was achieved through the application of known $\alpha$-nitrilium ion-mediated $\beta$-selective glycosylation methodology. An iterative glycosylation strategy was used for the assembly of the trirhamnan building block. A new route to the anthrose saccharide was developed from D-galactose.

\section{Introduction}

Due to the recent uses of Bacillus anthracis, a gram positive bacteria and the etiological agent of anthrax, ${ }^{1,2}$ as a biological weapon, inexpensive, effective methods of detection and vaccination against this organism are highly desired. The similarity of the B. anthracis sporecell-surface antigens with those of the opportunistic human pathogen $B$. cereus and other bacteria of this group complicates the design of reliable selective antibody-based detection systems. The spores of Bacillus anthracis are enclosed by a prominent loose fitting layer called the exosporium, which is the primary barrier of the spore and the source of the spore antigens, 3,4 and which interacts with the environment, detection devices and with spore-binding cells in the mammalian host and host defenses. The exosporium therefore plays an important role in the spore survival and/or pathogenesis. A highly immunogenic glycoprotein BclA, an important constituent of the exosporium, was found to be substituted with multiple copies of an $O$-linked oligosaccharide 1,5 which contains the previously unknown terminal substituent, 2-O-methyl-4-(3-hydroxy-3-methylbutylamino)-4,6-dideoxy-D-glucose. This sugar, which is also referred to as anthrose, appears to be specific for the spores of this bacteria as it was not found in spores of either Bacillus cereus or Bacillus thuringiensis, the most phylogenetically 
similar species. ${ }^{5}$ Thus, tetrasacchride $\mathbf{1}$ is a very attractive tool for the development of speciesspecific biomarkers, as well as of novel vaccines which target anthrax spores. In view of the fact that pure cell surface oligosaccharides are often difficult to obtain by isolation, effective synthetic approaches to the tetrasaccharide and its analogs are highly desirable.

Since its isolation in $2004,{ }^{5}$ the preparation of several synthetic tri- 6 and tetrasaccharide ${ }^{7-}$ 10,11 analogs of 1 has been reported in the literature (Fig. 1). The first total synthesis described, that of the tetrasaccharide analog 2,7 featured a terminal pentenyl group, which served as a convenient point of attachment to a carrier protein in vaccine development. In this first synthesis a convergent approach was utilized to facilitate access to analogs and shorter sequences, and assembly of the terminal anthrose was accomplished in a short, straightforward way starting from D-fucose. A different [3+1] tack was taken in the synthesis of $3 ; 8-10$ both a stepwise approach in the direction of the proceeding from the downstream toward the upstream end of the oligosaccharide, $, 9,10,12$ as well as sequential glycosylation with different types of glycosyl donors ${ }^{8}$ were explored in the construction of the trirhamnan. In this second approach the terminal anthrose building block was synthesized by a more lengthy strategy from a 4-azido-4,6-dideoxy-D-mannose derivative. ${ }^{13-16}$ A similar, [2+1] approach was taken for the synthesis of trisaccharide analogs $4-7,6$ but in this case an azido deoxy galactose derivative ${ }^{17}$ was used as precursor of the terminal anthrose unit.

Despite the different overall strategies, these syntheses have many points in common. First, glycosylation with neighboring group (bromoacetyl or levulinoyl) participation was used in the construction of the $\beta$-linkage to the terminal anthrose unit, ${ }^{7-10}$ thereby necessitating subsequent removal of the protecting group at 2-position and then methylation. ${ }^{18}$ Second, $\alpha$ selectivity in the rhamnosylation reactions was achieved in all but one case by anchimeric assistance. ${ }^{6,7}$ In all cases the synthesis of the anthrose building block required extensive protective group manipulations, ${ }^{13-16}$ or an expensive starting material. ${ }^{7 n}$ in lanning our synthesis of $\mathbf{2}$ in a [3+1] manner, we wanted to address these problems through a) application of known $\alpha$-nitrilium mediated $\beta$-selective glycosylation 19,20 methodology for the construction of the 1,2-trans glycosidic linkage in the terminal anthrose moiety; $b$ ) the straightforward assembly of the rhamnan building block through the recently developed iterative glycosylation strategy ${ }^{21}$ using thiorhamnoside donors, known to give good $\alpha$ selectivity without neighboring group participation; and c) developing a new, shorter route to the anthrose saccharide, utilizing inexpensive D-galactose as a precursor.

\section{Results and Discussion}

We began our synthesis of the anthrose monosaccharide building block with the galactose derivative $\mathbf{8}$, which is readily available from D-galactose in 4 steps (Scheme 1). ${ }^{22}$ Regioselective installation of a 2-naphthylmethyl (Nap) ${ }^{23-25}$ group at the 3-position through the intermediacy of a tin acetal, 26,27 followed by methylation, gave 10 . Deprotection in acidic media, followed by regioselective substitution of the primary 6-OH in the presence of the secondary 4-OH with a phenylseleno group 28 gave 12. Reduction with tributyltin hydride 29 , 30 gave the 6-deoxygalactose derivative 13. Displacement of the 4- $O$-triflate leaving group, introduced by the reaction of $\mathbf{1 3}$ with triflic anhydride, with azide gave desired donor $\mathbf{1 4}$.

With 14 in hand, we proceeded to the synthesis of the trirhamnan building blocks. Benzylation of known n-pentenyl rhamnoside $\mathbf{1 5},{ }^{31}$ readily available through Fischer glycosylation of Lrhamnose and further acetonide protection, ${ }^{31}$ gave 16 (Scheme 2). Cleavage of the 2,3-Oisopropylidene group in acidic media, followed by stannyl activated regioselective benzylation, gave $\mathbf{1 7}, 7$ which was converted, using a known procedure, ${ }^{32}$ to the desired dibromide acceptor 18. Building block $19^{33}$ was synthesized using a known procedure ${ }^{33}$ and then converted to 
the acceptor 20,33 following the protocol outlined in Scheme 3. A higher yield of $\mathbf{2 0}$ was achieved by utilizing a mixture of methanol and dichloromethane as a solvent.

The assembly of the trirhamnan moiety $\mathbf{2 2}$ started with preactivation of donor $\mathbf{1 9}$, followed by the addition of acceptor $\mathbf{2 0}$. Subsequent quenching of the reaction mixture with triethyl phosphite $^{34,35}$ provided disaccharide $\mathbf{2 1}$, predominantly as the $\alpha$-anomer. In a similar manner, but omitting the quenching step, $\mathbf{2 1 \alpha}$ was allowed to react with 18, to give the crude trisaccharide, which was further deprotected under oxidative conditions to give the desired trisaccharide building block 22 (Scheme 4).

In order to find an optimal promoter/solvent combination for the synthesis of the tetrasaccharide, the glycosylation of donor $\mathbf{1 4}$ was investigated using model acceptor $\mathbf{2 3}^{36}$ and the activation systems outlined in Scheme 5. In the case of preactivation of $\mathbf{1 4}$ with 1benzenesulfinyl piperidine (BSP)/ $\mathrm{Tf}_{2} \mathrm{O}^{37}$ in the presence of 2,4,6-tri-tert-butylpyrimidine (TTBP) and subsequent addition of acceptor 23 , a considerable improvement in the $\beta$ selectivity was observed, as expected, when the solvent was changed from dichloromethane to propionitrile. ${ }^{19,20}$ Use of analogous promoters $\left(\mathrm{Ph}_{2} \mathrm{SO},{ }^{35} 1\right.$ or 2 eq) did not improve the selectivity. However, activation of the donor $\mathbf{1 4}$ in the presence of acceptor $\mathbf{2 3}$ by the NIS/ TfOH system ${ }^{38-40}$ resulted in a significant enhancement of the stereoselectivity, as well as in the overall yield of the reaction.

To complete the synthesis, the precursor to the anthrose unit was coupled to trisaccharide $\mathbf{2 2}$ using the optimal NIS/TfOH/propionitrile conditions to afford $\mathbf{2 5}$ as an approximately 3:1 $\beta: \alpha$-mixture of anomers in $92 \%$ overall yield. Thus, the increased efficiency of the direct introduction of the anthrose moiety in this manner is achieved at the expense of some loss of selectivity. Debromination 32 of $\mathbf{2 5 \beta}$ gave $\mathbf{2 6}$ from which oxidative cleavage of the 2naphthylmethyl group afforded tetrasaccharide $\mathbf{2 7}$, suitable for further modifications in the terminal anthrose moiety, such as were found to be essential for the constitution of the highly specific antigenic determinant. ${ }^{41}$ The moderate yield of $\mathbf{2 7}$ is attributable to the previously reported problem of the competing debenzylation reactions in the course of the DDQ promoted cleavage of 2-naphthylmethyl/p-methoxyphenyl ethers. ${ }^{33}$ To overcome this difficulty the mixture of debenzylated byproducts of the 2-naphthylmethyl deprotection reaction was benzylated under standard conditions to give $\mathbf{2 8}$, suitable for further transformations to the target molecule through the same routes as $\mathbf{2 7}$. Final removal of the benzyl protecting groups and transformation of azide moiety to the amine was achieved by application of sodium in liquid ammonia to the mixture of $\mathbf{2 7}$ and $\mathbf{2 8}$. Subsequent coupling to the 3-hydroxy-3methylbutyric acid under peptide-coupling conditions ${ }^{42}$ led to the tetrasaccharide 2 , whose spectroscopic data was identical to that previously reported (Scheme 6). ${ }^{7}$

In conclusion, a synthesis of an antigenic tetrasaccharide from Bacillus anthracis has been accomplished in a [3+1] manner. A straightforward route to the anthrose building block from D-galactose was developed in which no extensive protective group manipulations or expensive starting materials were necessary. The assembly of the trirhamnan building block via an iterative glycosylation strategy, and the construction of the 1,2-trans-glycosidic linkage to the terminal anthrose moiety through the $\alpha$-nitrilium ion-mediated $\beta$-selective glycosylation methodology, enables the use of a minimal protecting group strategy and increases the efficiency of the overall synthesis. 


\section{Experimental Section}

\section{General}

Unless otherwise noted, reactions were conducted under an inert atmosphere of argon or nitrogen. All ${ }^{1} \mathrm{H}$ and ${ }^{13} \mathrm{C}$ spectra were recorded in $\mathrm{CDCl}_{3}$, except for $\mathbf{2}$, where $\mathrm{CD}_{3} \mathrm{OD}$ was used as a solvent.

\section{S-Phenyl 4,6-O-Benzylidene-3-O-(2-naphthylmethyl)- $\beta$-D-thiogalactopyranoside (9)}

A suspension of $\mathbf{8}^{22}(490 \mathrm{mg}, 1.36 \mathrm{mmol})$ and dibutyltin oxide $(610 \mathrm{mg}, 2.45 \mathrm{mmol})$ in toluene $(7 \mathrm{~mL})$ was heated to reflux in a Dean-Stark apparatus for $4 \mathrm{~h}$, after which most of the solvent was distilled off. The reaction mixture was cooled to room temperature and the residual solvent was evaporated under reduced pressure. $\mathrm{CsF}$ (414 mg, $2.72 \mathrm{mmol})$, 2-(bromomethyl) naphthalene ( $602 \mathrm{mg}, 2.72 \mathrm{mmol})$, tetrabutylammonium iodide (1.00 g, $2.72 \mathrm{mmol})$, and DMF $(6 \mathrm{~mL})$ were then added. The reaction mixture was heated to reflux overnight, diluted with ethyl acetate, washed (sat. aq. $\mathrm{NaHCO}_{3}$, brine), dried $\left(\mathrm{Na}_{2} \mathrm{SO}_{4}\right)$, and concentrated. Purification by column chromatography $\left(\mathrm{SiO}_{2}, 1 / 9\right.$ to $1 / 3$ ethyl acetate/hexanes) gave $9(490 \mathrm{mg}, 60 \%)$ as a white solid. M.p. ${ }^{175-176}{ }^{\circ} \mathrm{C}$. $[\alpha]^{21} \mathrm{D}+32.4\left(c \mathrm{c} 0.38, \mathrm{CHCl}_{3}\right) .{ }^{1} \mathrm{H}$ NMR $(400 \mathrm{MHz}) \delta: 7.73-$ $7.85(\mathrm{~m}, 4 \mathrm{H}), 7.66-7.72(\mathrm{~m}, 2 \mathrm{H}), 7.44-7.52(\mathrm{~m}, 3 \mathrm{H}), 7.34-7.44(\mathrm{~m}, 5 \mathrm{H}), 7.22-7.32(\mathrm{~m}$, $3 \mathrm{H}), 5.42(\mathrm{~s}, 1 \mathrm{H}), 4.90(\mathrm{~s}, 2 \mathrm{H}), 4.51(\mathrm{~d}, J=9.5 \mathrm{~Hz}, 1 \mathrm{H}), 4.34(\mathrm{dd}, J=12.3,1.6 \mathrm{~Hz}, 1 \mathrm{H}), 4.15$ $(\mathrm{dd}, J=3.4,0.7 \mathrm{~Hz}, 1 \mathrm{H}), 3.92-4.02(\mathrm{~m}, 2 \mathrm{H}), 3.56(\mathrm{dd}, J=9.3,3.3 \mathrm{~Hz}, 1 \mathrm{H}), 3.41-3.43(\mathrm{~m}$, $1 \mathrm{H}), 2.52(\mathrm{~d}, J=1.9 \mathrm{~Hz}, 1 \mathrm{H}) ;{ }^{13} \mathrm{C}$ NMR $(101 \mathrm{MHz}) \delta: 137.8,135.5,133.8,133.2,133.1,130.6$, $129.1128 .9,128.3,128.2,127.9,127.7,126.8,126.6,126.2,126.1,125.8,101.2,87.1,80.2$, 73.4, 71.9, 70.1, 69.4, 67.3; ESIHRMS Calcd for $\mathrm{C}_{30} \mathrm{H}_{28} \mathrm{NaO}_{5} \mathrm{~S}[\mathrm{M}+\mathrm{Na}]^{+}:$523.1555. Found 523.1562 .

\section{S-Phenyl 4,6-O-Benzylidene-2-O-methyl-3-O-(2-naphthylmethyl)- $\beta$-D-thiogalacto- pyranoside (10)}

A solution of $9(9.34 \mathrm{~g}, 18.7 \mathrm{mmol})$ in DMF $(300 \mathrm{~mL})$ was cooled to $-15^{\circ} \mathrm{C}, \mathrm{NaH}(60 \%$ in mineral oil, $1.12 \mathrm{~g}, 28.0 \mathrm{mmol}$ ) was added slowly and the reaction mixture was allowed to stir for $30 \mathrm{~min}$ at this temperature. Methyl iodide $(1.98 \mathrm{~mL}, 31.7 \mathrm{mmol})$ was then added slowly and the reaction mixture was allowed to warm up to r.t. and stirred overnight. The reaction mixture was quenched with $\mathrm{MeOH}$, diluted with $\mathrm{CHCl}_{3}$, washed (water, brine), dried $\left(\mathrm{Na}_{2} \mathrm{SO}_{4}\right)$, and concentrated. Purification by column chromatography $\left(\mathrm{SiO}_{2}, 1 / 4\right.$ ethyl acetate/ hexanes) gave $10(7.7 \mathrm{~g}, 80 \%)$ as a white solid. M.p. $174-176^{\circ} \mathrm{C}$. $[\alpha]^{21} \mathrm{D}+28.4(c 0.40$, $\left.\mathrm{CHCl}_{3}\right){ }^{1} \mathrm{H}$ NMR $(400 \mathrm{MHz}) \delta: 7.76-7.87(\mathrm{~m}, 4 \mathrm{H}), 7.68-7.73(\mathrm{~m}, 2 \mathrm{H}), 7.45-7.55(\mathrm{~m}, 5 \mathrm{H})$, $7.36-7.43(\mathrm{~m}, 3 \mathrm{H}), 7.19-7.27(\mathrm{~m}, 3 \mathrm{H}), 5.46(\mathrm{~s}, 1 \mathrm{H}), 4.93(\mathrm{~d}, J=12.7 \mathrm{~Hz}, 1 \mathrm{H}), 4.86(\mathrm{~d}, J=$ $12.6 \mathrm{~Hz}, 1 \mathrm{H}), 4.49(\mathrm{~d}, J=9.4 \mathrm{~Hz}, 1 \mathrm{H}), 4.33(\mathrm{dd}, J=12.3,1.5 \mathrm{~Hz}, 1 \mathrm{H}), 4.12(\mathrm{dd}, J=3.4,0.7$ $\mathrm{Hz}, 1 \mathrm{H}), 3.94(\mathrm{dd}, J=12.4,1.6 \mathrm{~Hz}, 1 \mathrm{H}), 3.64(\mathrm{t}, J=9.2 \mathrm{~Hz}, 1 \mathrm{H}), 3.59$ (s, 3H), 3.57 (dd, $J=$ 9.2, 3.4 Hz, $1 \mathrm{H}), 3.35-3.37(\mathrm{~m}, 1 \mathrm{H}) ;{ }^{13} \mathrm{C}$ NMR $(101 \mathrm{MHz}) \delta: 137.9,135.7,133.2,133.0$, 132.9, 132.6, 129.1, 128.8, 128.2, 127.9, 127.7, 127.5, 126.7, 126.6, 126.2, 126.0, 125.8, 101.4, 86.4, 81.1, 76.9, 74.0, 72.1, 69.8, 69.4, 61.1; ESIHRMS Calcd for $\mathrm{C}_{31} \mathrm{H}_{30} \mathrm{NaO}_{5} \mathrm{~S}[\mathrm{M}+\mathrm{Na}]^{+}$: 537.1712. Found 537.1696.

\section{S-Phenyl 2-O-Methyl-3-O-(2-naphthylmethyl)- $\beta$-D-thiogalactopyranoside (11)}

A mixture of $10(510 \mathrm{mg}, 1.0 \mathrm{mmol}), p$-toluenesulfonic acid monohydrate $(19 \mathrm{mg}, 0.1 \mathrm{mmol})$ and $\mathrm{MeOH}(10 \mathrm{~mL})$ was heated to reflux for $45 \mathrm{~min}$, then cooled to r.t., diluted with ethyl acetate, washed (sat. aq. $\mathrm{NaHCO}_{3}$, brine), dried $\left(\mathrm{Na}_{2} \mathrm{SO}_{4}\right)$, and concentrated. Purification by column chromatography $\left(\mathrm{SiO}_{2}, 2 / 3\right.$ to $1 / 1$ ethyl acetate/hexanes) gave $\mathbf{1 1}(401 \mathrm{mg}, 95 \%)$ as a

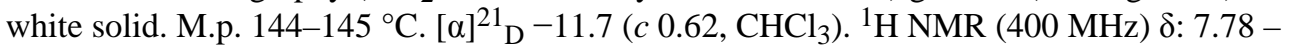
$7.87(\mathrm{~m}, 4 \mathrm{H}), 7.46-7.57(\mathrm{~m}, 5 \mathrm{H}), 7.22-7.32(\mathrm{~m}, 3 \mathrm{H}), 4.88(\mathrm{~s}, 2 \mathrm{H}), 4.54(\mathrm{~d}, J=9.2 \mathrm{~Hz}, 1 \mathrm{H})$, $4.02-4.05(\mathrm{~m}, 1 \mathrm{H}), 3.90-3.98(\mathrm{~m}, 1 \mathrm{H}), 3.73-3.81(\mathrm{~m}, 1 \mathrm{H}), 3.65(\mathrm{~s}, 3 \mathrm{H}), 3.42-3.55(\mathrm{~m}$, 


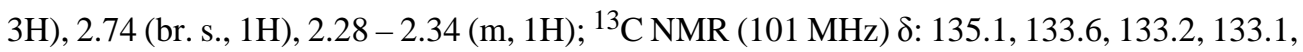
131.7, 129.0, 128.5, 127.9, 127.8, 127.5, 126.8, 126.4, 126.2, 125.7, 87.4, 82.1, 78.8, 78.0, 72.4, 67.6, 62.7, 61.4; ESIHRMS Calcd for $\mathrm{C}_{24} \mathrm{H}_{26} \mathrm{NaO}_{5} \mathrm{~S}[\mathrm{M}+\mathrm{Na}]^{+}: 449.1399$. Found 449.1391 .

\section{S-Phenyl 2-O-Methyl-3-O-(2-naphthylmethyl)-6-deoxy-6-phenylseleno- $\beta$-D-thio- galactopyranoside (12)}

A mixture of 11 (1.06 g, $2.49 \mathrm{mmol})$, diphenyl diselenide ( $3.89 \mathrm{~g}, 12.47 \mathrm{mmol})$, tributylphosphine $(4.3 \mathrm{~mL}, 17.43 \mathrm{mmol})$, and toluene $(20 \mathrm{~mL})$ was heated to reflux for $24 \mathrm{~h}$. Concentration of the reaction mixture, followed by purification by column chromatography $\left(\mathrm{SiO}_{2}\right.$, hexanes to $2 / 3$ ethyl acetate/hexanes) gave $12(1.09 \mathrm{~g}, 77 \%)$ as a white solid. M.p. 128$132{ }^{\circ} \mathrm{C} .[\alpha]^{21} \mathrm{D}+16.4\left(c 1.01, \mathrm{CHCl}_{3}\right) .{ }^{1} \mathrm{H}$ NMR $(500 \mathrm{MHz}) \delta: 7.78-7.88(\mathrm{~m}, 4 \mathrm{H}), 7.58-7.63$ $(\mathrm{m}, 2 \mathrm{H}), 7.43-7.54(\mathrm{~m}, 5 \mathrm{H}), 7.18-7.34(\mathrm{~m}, 6 \mathrm{H}), 4.87(\mathrm{~s}, 2 \mathrm{H}), 4.48(\mathrm{~d}, J=9.5 \mathrm{~Hz}, 1 \mathrm{H}), 4.12$ $(\mathrm{t}, J=2.5 \mathrm{~Hz}, 1 \mathrm{H}), 3.65(\mathrm{~s}, 3 \mathrm{H}), 3.41-3.52(\mathrm{~m}, 3 \mathrm{H}), 3.30(\mathrm{dd}, J=12.8,6.7 \mathrm{~Hz}, 1 \mathrm{H}), 3.18(\mathrm{dd}$, $J=12.7,7.2 \mathrm{~Hz}, 1 \mathrm{H}), 2.36(\mathrm{~d}, J=1.8 \mathrm{~Hz}, 1 \mathrm{H}) ;{ }^{13} \mathrm{C} \mathrm{NMR}(126 \mathrm{MHz}) \delta: 135.1,133.7,133.2$, $133.1,132.6,132.1,129.7,129.2,128.9,128.5,127.9,127.8,127.5,127.1,126.8,126.3,126.2$, 125.8, 87.7, 82.4 78.7, 77.6, 72.5, 67.5, 61.3, 27.5; ESIHRMS Calcd for $\mathrm{C}_{30} \mathrm{H}_{30} \mathrm{NaO}_{4} \mathrm{SSe}[\mathrm{M}$ $+\mathrm{Na}]^{+}: 589.0928$. Found 589.0900.

\section{S-Phenyl 2-O-Methyl-3-O-(2-naphthylmethyl)- $\beta$-D-thiofucopyranoside (13)}

A solution of 12 ( $820 \mathrm{mg}, 1.45 \mathrm{mmol})$, AIBN (98 mg, $0.58 \mathrm{mmol})$, and $\mathrm{Bu}_{3} \mathrm{SnH}(576 \mu \mathrm{L}, 2.17$ $\mathrm{mmol})$ in benzene $(145 \mathrm{~mL})$ was heated to reflux for $3 \mathrm{~h}$. The solvent was evaporated and the residual syrup was dissolved in acetonitrile, washed twice with hexanes and concentrated. Filtration of the crude through a pad of silica gel (with ethyl acetate as an eluent), purification by radial chromatography $\left(\mathrm{SiO}_{2}, 1 / 19\right.$ to $1 / 4$ ethyl acetate/hexanes) gave $\mathbf{1 3}(504 \mathrm{mg}, 85 \%)$ as a white solid. M.p. ${ }^{108}-111^{\circ} \mathrm{C}$. $[\alpha]^{20}{ }_{\mathrm{D}}-11.2\left(\right.$ c $\left.0.33, \mathrm{CHCl}_{3}\right) .{ }^{1} \mathrm{H}$ NMR $(501 \mathrm{MHz}) \delta: 7.79-$ $7.87(\mathrm{~m}, 4 \mathrm{H}), 7.55-7.59(\mathrm{~m}, 2 \mathrm{H}), 7.46-7.53(\mathrm{~m}, 3 \mathrm{H}), 7.22-7.33(\mathrm{~m}, 3 \mathrm{H}), 4.89(\mathrm{~s}, 2 \mathrm{H}), 4.50$ $(\mathrm{d}, J=9.7 \mathrm{~Hz}, 1 \mathrm{H}), 3.80(\mathrm{~d}, J=2.8 \mathrm{~Hz}, 1 \mathrm{H}), 3.65(\mathrm{~s}, 3 \mathrm{H}), 3.51-3.55(\mathrm{~m}, 2 \mathrm{H}), 3.43(\mathrm{t}, J=9.4$ $\mathrm{Hz}, 1 \mathrm{H}), 2.33$ (br. s., $1 \mathrm{H}), 1.35$ (d, $J=6.6 \mathrm{~Hz}, 3 \mathrm{H}) ;{ }^{13} \mathrm{C}$ NMR $(126 \mathrm{MHz}) \delta: 135.3,133.9$, 133.2, 133.1, 132.0, 128.9, 128.5, 128.0, 127.8, 127.4, 126.8, 126.3, 126.2, 125.8, 87.4, 82.6, 78.7, 74.2, 72.3, 69.7, 61.4, 16.8; ESIHRMS Calcd for $\mathrm{C}_{24} \mathrm{H}_{26} \mathrm{NaO}_{4} \mathrm{~S}[\mathrm{M}+\mathrm{Na}]^{+}: 433.1450$. Found 433.1445 .

\section{S-Phenyl 4-Azido-4-deoxy-2-O-methyl-3-O-(2-naphthylmethyl)- $\beta$-D-thioquinovo-pyranoside} (14)

To a solution of $13(313 \mathrm{mg}, 0.76 \mathrm{mmol})$ and pyridine $(185 \mu \mathrm{L}, 2.29 \mathrm{mmol})$ in $\mathrm{CH}_{2} \mathrm{Cl}_{2}(7 \mathrm{~mL})$ $\mathrm{Tf}_{2} \mathrm{O}(256 \mu \mathrm{L}, 1.52 \mathrm{mmol})$ was added at $0{ }^{\circ} \mathrm{C}$. The reaction mixture was stirred for $1.5 \mathrm{~h}$ at r.t., diluted with $\mathrm{CH}_{2} \mathrm{Cl}_{2}$, washed (sat. aq. $\mathrm{NaHCO}_{3}$, brine), dried $\left(\mathrm{Na}_{2} \mathrm{SO}_{4}\right)$, and concentrated. The residue was dissolved in DMF (3 mL) and $\mathrm{NaN}_{3}(64 \mathrm{mg}, 0.98 \mathrm{mmol})$ was added. The reaction mixture was allowed to stir for $2.5 \mathrm{~h}$, diluted with ethyl acetate, washed (brine), dried $\left(\mathrm{Na}_{2} \mathrm{SO}_{4}\right)$, and concentrated. Filtration of the crude through a pad of silica gel (with ethyl acetate as an eluent) and purification by radial chromatography $\left(\mathrm{SiO}_{2}\right.$, hexanes to $1 / 19$ ethyl acetate/hexanes) gave $14(288 \mathrm{mg}, 87 \%)$ as a white solid. M.p. $85-86^{\circ} \mathrm{C}$. $[\alpha]^{23} \mathrm{D}+32.3(c 0.25$, $\left.\mathrm{CHCl}_{3}\right) .{ }^{1} \mathrm{H} \mathrm{NMR}(501 \mathrm{MHz}) \delta: 7.81-7.90(\mathrm{~m}, 4 \mathrm{H}), 7.46-7.59(\mathrm{~m}, 5 \mathrm{H}), 7.26-7.35(\mathrm{~m}, 3 \mathrm{H})$, $5.07(\mathrm{~d}, J=10.8 \mathrm{~Hz}, 1 \mathrm{H}), 5.02(\mathrm{~d}, J=10.8 \mathrm{~Hz}, 1 \mathrm{H}), 4.53(\mathrm{~d}, J=9.9 \mathrm{~Hz}, 1 \mathrm{H}), 3.67(\mathrm{~s}, 3 \mathrm{H})$, $3.51(\mathrm{t}, J=9.1 \mathrm{~Hz}, 1 \mathrm{H}), 3.20-3.28(\mathrm{~m}, 2 \mathrm{H}), 3.18(\mathrm{t}, J=9.6 \mathrm{~Hz}, 1 \mathrm{H}), 1.38(\mathrm{~d}, J=6.1 \mathrm{~Hz}$, $3 \mathrm{H}) ;{ }^{13} \mathrm{C}$ NMR (126 MHz) $\delta: 135.2,133.42,133.35,133.1,132.1,129.0,128.3,128.1,127.8$, 127.7, 127.2, 126.3, 126.2, 126.1, 87.4, 84.7, 83.0, 75.7, 74.8, 67.6, 61.2, 18.8; ESIHRMS Calcd for $\mathrm{C}_{24} \mathrm{H}_{25} \mathrm{NaN}_{3} \mathrm{O}_{3} \mathrm{~S}[\mathrm{M}+\mathrm{Na}]^{+}$: 458.1514. Found 458.1505. 


\section{n-Pentenyl 4-O-Benzyl-2,3-O-isopropylidene- $\alpha$-L-rhamnopyranoside (16)}

To a solution of $\mathbf{1 5}^{31}(1.46 \mathrm{~g}, 5.36 \mathrm{mmol})$ in DMF $(8 \mathrm{~mL}) \mathrm{NaH}(60 \%$ in mineral oil, $321 \mathrm{mg}$, $8.04 \mathrm{mmol}$ ) was added slowly at $0{ }^{\circ} \mathrm{C}$, followed by benzyl bromide $(961 \mu \mathrm{L}, 8.04 \mathrm{mmol})$, and the reaction mixture was allowed to stir for $3 \mathrm{~h}$ at r.t. The reaction mixture was diluted with ethyl acetate, washed (sat. aq. $\mathrm{NH}_{4} \mathrm{Cl}$, brine), dried $\left(\mathrm{Na}_{2} \mathrm{SO}_{4}\right)$, and concentrated. Filtration of the crude through a pad of silica gel (with ethyl acetate as an eluent), purification by radial chromatography $\left(\mathrm{SiO}_{2}\right.$, hexanes to $1 / 19$ ethyl acetate/hexanes) gave $\mathbf{1 6}(1.74 \mathrm{~g}, 90 \%)$ as a white solid. M.p. $38-39^{\circ} \mathrm{C} .[\alpha]^{19} \mathrm{D}-46.4\left(c 0.71, \mathrm{CHCl}_{3}\right) .{ }^{1} \mathrm{H}$ NMR $(500 \mathrm{MHz}) \delta: 7.26-7.40(\mathrm{~m}$, $5 \mathrm{H}), 5.77-5.86(\mathrm{~m}, 1 \mathrm{H}), 5.04$ (ddd, $J=17.1,3.1,1.5 \mathrm{~Hz}, 1 \mathrm{H}), 4.99$ (dq, $J=10.2,1.5 \mathrm{~Hz}, 1 \mathrm{H}$ ), $4.96(\mathrm{~s}, 1 \mathrm{H}), 4.92(\mathrm{~d}, J=11.6 \mathrm{~Hz}, 1 \mathrm{H}), 4.64(\mathrm{~d}, J=11.6 \mathrm{~Hz}, 1 \mathrm{H}), 4.27-4.31(\mathrm{~m}, 1 \mathrm{H}), 4.15$ $(\mathrm{d}, J=5.7 \mathrm{~Hz}, 1 \mathrm{H}), 3.66-3.74(\mathrm{~m}, 2 \mathrm{H}), 3.43(\mathrm{dt}, J=9.6,6.4 \mathrm{~Hz}, 1 \mathrm{H}), 3.23(\mathrm{dd}, J=9.8,7.1$ $\mathrm{Hz}, 1 \mathrm{H}), 2.09-2.17(\mathrm{~m}, 2 \mathrm{H}), 1.64-1.74(\mathrm{~m}, 2 \mathrm{H}), 1.53(\mathrm{~s}, 3 \mathrm{H}), 1.39$ (s, 3H), 1.29 (d, $J=6.2$ $\mathrm{Hz}, 3 \mathrm{H}) ;{ }^{13} \mathrm{C}$ NMR $(126 \mathrm{MHz}) \delta$ : 138.4, 138.0, 128.3, 128.0, 127.6, 115.0, 109.1, 97.0, 81.2, 78.7, 76.2, 73.0, 66.8, 64.5, 30.3, 28.6, 28.1, 26.4, 17.9; ESIHRMS Calcd for $\mathrm{C}_{21} \mathrm{H}_{30} \mathrm{NaO}_{5}[\mathrm{M}$ $+\mathrm{Na}]^{+}:$385.1991. Found 385.1980.

\section{n-Pentenyl 2,4-Di-O-benzyl-a-L-rhamnopyranoside (17)}

A mixture of $16(1.25 \mathrm{~g}, 3.45 \mathrm{mmol})$ and acetic acid $(80 \%$ in water, $10 \mathrm{~mL})$ was heated for $4 \mathrm{~h}$ at $90{ }^{\circ} \mathrm{C}$. Solvents were then evaporated and residual syrup was dried by addition of toluene, followed by evaporation (2 times). $\mathrm{Bu}_{2} \mathrm{SnO}(1.03 \mathrm{~g}, 4.14 \mathrm{mmol}$ ) was then added to this syrup, followed by benzene $(25 \mathrm{~mL})$ and mixture was heated to reflux in a Dean-Stark apparatus for $3 \mathrm{~h}$, after which most of the solvent was distilled off. The reaction mixture was cooled to r. t. and the residual solvent was evaporated under reduced pressure. CsF (1.05 g, $6.90 \mathrm{mmol})$, benzyl bromide $(536 \mu \mathrm{L}, 4.49 \mathrm{mmol})$ and $\mathrm{DMF}(20 \mathrm{~mL})$ were then added. The reaction mixture was allowed to stir overnight, diluted with ethyl acetate, washed (water, brine), dried $\left(\mathrm{Na}_{2} \mathrm{SO}_{4}\right)$, and concentrated. Filtration of the crude through a pad of silica gel (with ethyl acetate as an eluent), purification by radial chromatography $\left(\mathrm{SiO}_{2}\right.$, hexanes to 3/17 ethyl acetate/hexanes) gave 17 (1.06 g, 74\%). Spectral data matched that reported in literature. ${ }^{7}$

\section{4,5-Dibromopentyl 2,4-Di-O-benzyl- $\alpha$-L-rhamnopyranoside (18)}

A solution of 17 (300 mg, $0.73 \mathrm{mmol}$ ) in THF/acetonitrile $(3 \mathrm{~mL} / 6 \mathrm{~mL})$ was added to a mixture of $\mathrm{CuBr}_{2}(812 \mathrm{mg}, 3.64 \mathrm{mmol})$ and $\mathrm{LiBr}(632 \mathrm{mg}, 7.28 \mathrm{mmol})$ in THF/acetonitrile $(6 \mathrm{~mL} / 12$ $\mathrm{mL}$ ). The reaction mixture was stirred overnight in the dark at r.t., then diluted with ethyl acetate, washed (water, 2 times), dried $\left(\mathrm{Na}_{2} \mathrm{SO}_{4}\right)$, and concentrated. Filtration of the crude through a pad of silica gel (with ethyl acetate as an eluent) and purification by radial chromatography $\left(\mathrm{SiO}_{2}\right.$, hexanes to $1 / 4$ ethyl acetate/hexanes) gave $\mathbf{1 8}$ as a mixture of two diastereomers in the dibromopentyl chain $(370 \mathrm{mg}, 89 \%) .{ }^{1} \mathrm{H}$ NMR $(500 \mathrm{MHz}) \delta: 7.28-7.41$ (m, 10H), $4.91(\mathrm{~d}, J=10.8 \mathrm{~Hz}, 1 \mathrm{H}), 4.81(\mathrm{~d}, J=1.5 \mathrm{~Hz}, 1 \mathrm{H}), 4.72(\mathrm{~s}, 2 \mathrm{H}), 4.66(\mathrm{~d}, J=10.8$ $\mathrm{Hz}, 1 \mathrm{H}), 4.15-4.22(\mathrm{~m}, 1 \mathrm{H}), 4.01-4.04(\mathrm{~m}, 1 \mathrm{H}), 3.84-3.89(\mathrm{~m}, 2 \mathrm{H}), 3.69-3.77(\mathrm{~m}, 2 \mathrm{H})$, $3.63(\mathrm{t}, J=10.1 \mathrm{~Hz}, 1 \mathrm{H}), 3.48(\mathrm{t}, J=9.4 \mathrm{~Hz}, 1 \mathrm{H}), 3.42-3.47(\mathrm{~m}, 1 \mathrm{H}), 2.60(\mathrm{~s}, 1 \mathrm{H}), 2.20-2.30$ $(\mathrm{m}, 1 \mathrm{H}), 1.79-1.93(\mathrm{~m}, 2 \mathrm{H}), 1.67-1.76(\mathrm{~m}, 1 \mathrm{H}), 1.34(\mathrm{~d}, J=6.4 \mathrm{~Hz}, 3 \mathrm{H}) ;{ }^{13} \mathrm{C}$ NMR $(126$ MHz) $\delta: 138.4,137.9,128.6,128.5,128.1,128.0,127.9,127.8,99.1,99.0,80.0,75.5,72.1$, 68.6, 67.5, 66.54, 66.51, 52.6, 52.5, 36.2, 33.01, 32.95, 26.9, 18.0; ESIHRMS Calcd for $\mathrm{C}_{25} \mathrm{H}_{32} \mathrm{NaBr}_{2} \mathrm{O}_{5}[\mathrm{M}+\mathrm{Na}]^{+}:$593.0514. Found 593.0519.

\section{S-Phenyl 2,4-Di-O-benzyl-a-L-thiorhamnopyranoside (20)}

To a solution of $\mathbf{1 9}^{33}(1.83 \mathrm{~g}, 3.17 \mathrm{mmol})$ in $\mathrm{MeOH} / \mathrm{CH}_{2} \mathrm{Cl}_{2}(10 \mathrm{~mL} / 30 \mathrm{~mL})$ DDQ $(2.16 \mathrm{~g}$, $9.51 \mathrm{mmol}$ ) was added at $0{ }^{\circ} \mathrm{C}$. After $30 \mathrm{~min}$, the reaction mixture was warmed to r. t. and stirred for a further $5 \mathrm{~h}$ before it was diluted with $\mathrm{CH}_{2} \mathrm{Cl}_{2}$ and quenched with sat. aq. $\mathrm{Na}_{2} \mathrm{CO}_{3}$. The organic phase was separated, washed (sat. aq. $\left.\mathrm{Na}_{2} \mathrm{CO}_{3}\right)$, dried $\left(\mathrm{Na}_{2} \mathrm{SO}_{4}\right)$, and concentrated. Filtration of the crude through a pad of silica gel (with ethyl acetate as an eluent), 
purification by radial chromatography $\left(\mathrm{SiO}_{2}\right.$, hexanes to $1 / 9$ ethyl acetate/hexanes) gave $\mathbf{2 0}$ $(1.03 \mathrm{~g}, 74 \%)$, whose spectral data matched that reported in literature. ${ }^{33}$

\section{S-Phenyl 2,4-Di-O-benzyl-3-O-(2-naphthylmethyl)- $\alpha$-L-rhamnopyranosyl-(1 $\rightarrow$ 3)-2,4-di-O- benzyl- $\alpha$-L-thiorhamnopyranoside (21 $\alpha$ ) and S-Phenyl 2,4-Di-O-benzyl-3-O-(2- naphthylmethyl)- $\beta$-L-rhamnopyranosyl-(1 $\rightarrow 3)-2,4-d i-O$-benzyl- $\alpha$-L-thiorhamno-pyranoside $(21 \beta)$}

To a solution of 19 (304 mg, $0.53 \mathrm{mmol})$, TTBP (262 mg, $1.05 \mathrm{mmol}), \mathrm{Ph}_{2} \mathrm{SO}$ (107 mg, 0.53 mmol), and activated $3 \AA$ powdered molecular sieves in $\mathrm{CH}_{2} \mathrm{Cl}_{2}(10 \mathrm{~mL}) \mathrm{Tf}_{2} \mathrm{O}(98 \mu \mathrm{L}, 0.58$ mmol) was added at $-60{ }^{\circ} \mathrm{C}$. The reaction mixture was stirred for $1 \mathrm{~h}$ at this temperature and solution of 20 ( $391 \mathrm{mg}, 0.90 \mathrm{mmol}$ ) in $\mathrm{CH}_{2} \mathrm{Cl}_{2}(4 \mathrm{~mL})$ was added dropwise. The reaction mixture was stirred for an additional $30 \mathrm{~min}$ at $-60{ }^{\circ} \mathrm{C}$ and then quenched by the addition of $\mathrm{P}(\mathrm{OEt})_{3}(184 \mu \mathrm{L}, 1.05 \mathrm{mmol})$. The reaction mixture was warmed r.t., then filtered, diluted with $\mathrm{CH}_{2} \mathrm{Cl}_{2}$, washed (sat. aq. $\left.\mathrm{Na}_{2} \mathrm{CO}_{3}\right)$, dried $\left(\mathrm{Na}_{2} \mathrm{SO}_{4}\right)$, and concentrated. Filtration of the crude through a pad of silica gel (with ethyl acetate as an eluent), purification by radial chromatography $\left(\mathrm{SiO}_{2}\right.$, hexanes to 1/9 ethyl acetate/hexanes), followed by the HPLC $\left(\mathrm{SiO}_{2}\right.$, hexanes to 1/9 ethyl acetate/hexanes) gave $\mathbf{2 1 \alpha}(235 \mathrm{mg}, 49 \%), \mathbf{2 1 \beta}(34 \mathrm{mg}, 7 \%)$ and $\mathbf{2 0}(70$ mg, $18 \%)$ was recovered. 21 $\alpha .[\alpha]^{24} \mathrm{D}-61.2\left(c 0.20, \mathrm{CHCl}_{3}\right) .{ }^{1} \mathrm{H}$ NMR $(501 \mathrm{MHz}) \delta: 7.66-$ $7.83(\mathrm{~m}, 4 \mathrm{H}), 7.41-7.49(\mathrm{~m}, 5 \mathrm{H}), 7.35-7.40(\mathrm{~m}, 6 \mathrm{H}), 7.18-7.35(\mathrm{~m}, 17 \mathrm{H}), 5.52(\mathrm{~s}, 1 \mathrm{H})$, $5.18(\mathrm{~s}, 1 \mathrm{H}), 5.04(\mathrm{~d}, J=11.2 \mathrm{~Hz}, 1 \mathrm{H}), 4.78(\mathrm{~d}, J=12.1 \mathrm{~Hz}, 1 \mathrm{H}), 4.67-4.74(\mathrm{~m}, 3 \mathrm{H}), 4.60$ $(\mathrm{d}, J=11.9 \mathrm{~Hz}, 1 \mathrm{H}), 4.45-4.55(\mathrm{~m}, 4 \mathrm{H}), 4.12-4.20(\mathrm{~m}, 1 \mathrm{H}), 4.07(\mathrm{dd}, J=9.5,2.9 \mathrm{~Hz}, 1 \mathrm{H})$, $4.01-4.04(\mathrm{~m}, 1 \mathrm{H}), 3.99(\mathrm{dd}, J=9.5,3.0 \mathrm{~Hz}, 1 \mathrm{H}), 3.81-3.88(\mathrm{~m}, 1 \mathrm{H}), 3.73-3.76(\mathrm{~m}, 1 \mathrm{H})$, $3.70(\mathrm{t}, J=9.4 \mathrm{~Hz}, 1 \mathrm{H}), 3.58(\mathrm{t}, J=9.4 \mathrm{~Hz}, 1 \mathrm{H}), 1.35(\mathrm{~d}, J=6.2 \mathrm{~Hz}, 3 \mathrm{H}), 1.30(\mathrm{~d}, J=6.2 \mathrm{~Hz}$, $3 \mathrm{H}) ;{ }^{13} \mathrm{C}$ NMR (126 MHz) $\delta: 139.0,138.4,137.8,136.0,134.6,133.3,133.0,131.5,129.1$, $128.6,128.5,128.4,128.3,128.1,128.0,127.9,127.84,127.81,127.71,127.66,127.6,127.5$, $127.4,127.0,126.5,126.1,125.9,99.9\left({ }^{1} J_{\mathrm{CH}}=168.7 \mathrm{~Hz}\right), 85.5\left({ }^{1} J_{\mathrm{CH}}=164.9 \mathrm{~Hz}\right), 80.8,80.5$, 79.9, 79.6, 76.0, 75.2, 74.7, 72.6, 72.5, 72.2, 69.5, 68.9, 18.2, 17.9; ESIHRMS Calcd for $\mathrm{C}_{57} \mathrm{H}_{58} \mathrm{NaO}_{8} \mathrm{~S}[\mathrm{M}+\mathrm{Na}]^{+}: 925.3750$. Found 925.3741. 21及. $[\alpha]^{22}{ }_{\mathrm{D}}+7.4\left(c 0.50, \mathrm{CHCl}_{3}\right) .{ }^{1} \mathrm{H}$ NMR (501 MHz) $\delta: 7.69-7.86(\mathrm{~m}, 4 \mathrm{H}), 7.37-7.51(\mathrm{~m}, 9 \mathrm{H}), 7.26-7.37(\mathrm{~m}, 13 \mathrm{H}), 7.18-$ $7.25(\mathrm{~m}, 6 \mathrm{H}), 5.54(\mathrm{~d}, J=2.9 \mathrm{~Hz}, 1 \mathrm{H}), 5.05(\mathrm{~d}, J=10.6 \mathrm{~Hz}, 1 \mathrm{H}), 5.01(\mathrm{~d}, J=10.8 \mathrm{~Hz}, 1 \mathrm{H})$, $5.00(\mathrm{~d}, J=12.5 \mathrm{~Hz}, 1 \mathrm{H}), 4.92(\mathrm{~d}, J=12.5 \mathrm{~Hz}, 1 \mathrm{H}), 4.66-4.75(\mathrm{~m}, 2 \mathrm{H}), 4.69(\mathrm{~d}, J=12.1 \mathrm{~Hz}$, $1 \mathrm{H}), 4.63(\mathrm{~d}, J=12.1 \mathrm{~Hz}, 1 \mathrm{H}), 4.55(\mathrm{~d}, J=10.6 \mathrm{~Hz}, 1 \mathrm{H}), 4.48(\mathrm{~d}, J=12.3 \mathrm{~Hz}, 1 \mathrm{H}), 4.29(\mathrm{~s}$, $1 \mathrm{H}), 4.18(\mathrm{dd}, J=7.9,3.1 \mathrm{~Hz}, 1 \mathrm{H}), 4.11-4.17(\mathrm{~m}, 1 \mathrm{H}), 3.91(\mathrm{t}, J=3.0 \mathrm{~Hz}, 1 \mathrm{H}), 3.82(\mathrm{~d}, J=$ $2.9 \mathrm{~Hz}, 1 \mathrm{H}), 3.63-3.70(\mathrm{~m}, 2 \mathrm{H}), 3.40(\mathrm{dd}, J=9.5,3.0 \mathrm{~Hz}, 1 \mathrm{H}), 3.22-3.29(\mathrm{~m}, 1 \mathrm{H}), 1.39(\mathrm{~d}$, $J=6.2 \mathrm{~Hz}, 3 \mathrm{H}), 1.37(\mathrm{~d}, J=6.1 \mathrm{~Hz}, 3 \mathrm{H}) ;{ }^{13} \mathrm{C}$ NMR $(126 \mathrm{MHz}) \delta: 138.9,138.7,138.6,137.7$, 135.9, 134.8, 133.3, 133.0, 131.6, 129.1, 128.5, 128.44, 128.37, 128.24, 128.18, 128.14, $128.10,128.0,127.9,127.8,127.6,127.4,127.3,126.2,125.9,125.6,99.0\left({ }^{1} J_{\mathrm{CH}}=154.9 \mathrm{~Hz}\right)$, $85.4\left({ }^{1} J_{\mathrm{CH}}=166.2 \mathrm{~Hz}\right), 82.2,80.3,80.2,76.5,76.3,75.5,74.7,74.3,74.1,72.12,72.09,71.6$, 69.0, 18.4, 18.2; ESIHRMS Calcd for $\mathrm{C}_{57} \mathrm{H}_{58} \mathrm{NaO}_{8} \mathrm{~S}[\mathrm{M}+\mathrm{Na}]^{+}$: 925.3750. Found 925.3744.

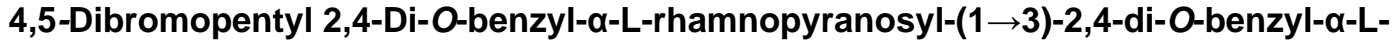

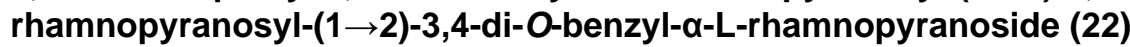

To a solution of $21 \boldsymbol{\alpha}$ ( $677 \mathrm{mg}, 0.75 \mathrm{mmol}$ ), TTBP (373 mg, $1.50 \mathrm{mmol}), \mathrm{Ph}_{2} \mathrm{SO}$ (151 mg, 0.75 mmol), and activated $3 \AA$ powdered molecular sieves in $\mathrm{CH}_{2} \mathrm{Cl}_{2}(22 \mathrm{~mL}) \mathrm{Tf}_{2} \mathrm{O}(139 \mu \mathrm{L}, 0.82$ $\mathrm{mmol}$ ) was added at $-60{ }^{\circ} \mathrm{C}$. The reaction mixture was stirred for $1 \mathrm{~h}$ at this temperature, and solution of $18(644 \mathrm{mg}, 1.13 \mathrm{mmol})$ in $\mathrm{CH}_{2} \mathrm{Cl}_{2}(7 \mathrm{~mL})$ was added dropwise. After stirring for $30 \mathrm{~min}$ at $-60{ }^{\circ} \mathrm{C}$ the reaction mixture was warmed r.t., then filtered, diluted with $\mathrm{CH}_{2} \mathrm{Cl}_{2}$, washed (sat. aq. $\left.\mathrm{Na}_{2} \mathrm{CO}_{3}\right)$, dried $\left(\mathrm{Na}_{2} \mathrm{SO}_{4}\right)$, and concentrated. The crude was filtered through a pad of silica gel (with ethyl acetate as an eluent) and purified by radial chromatography $\left(\mathrm{SiO}_{2}\right.$, hexanes to $1 / 9$ ethyl acetate/hexanes). Fractions containing product were combined and concentrated to give clear oil. To a solution of this oil in $\mathrm{CH}_{2} \mathrm{Cl}_{2} / \mathrm{MeOH}(18 \mathrm{~mL} / 6 \mathrm{~mL}) \mathrm{DDQ}$ $\left(400 \mathrm{mg}, 1.76 \mathrm{mmol}\right.$ ) was added at $0{ }^{\circ} \mathrm{C}$. After $30 \mathrm{~min}$, the reaction mixture was warmed to $\mathrm{r}$. 
t. and further stirred for $9 \mathrm{~h}$ before it was diluted with $\mathrm{CH}_{2} \mathrm{Cl}_{2}$ and quenched with sat. aq. $\mathrm{Na}_{2} \mathrm{CO}_{3}$. The organic phase was separated, washed (sat. aq. $\mathrm{Na}_{2} \mathrm{CO}_{3}$ ), dried $\left(\mathrm{Na}_{2} \mathrm{SO}_{4}\right)$, and concentrated. Filtration of the crude through a pad of silica gel (with ethyl acetate as an eluent), purification by radial chromatography $\left(\mathrm{SiO}_{2}\right.$, hexanes to $3 / 17$ ethyl acetate/hexanes) gave $\mathbf{2 2}$ as a mixture of two diastereomers in the dibromopentyl chain (413 mg, 45\%, 2 steps). ${ }^{1} \mathrm{H}$ NMR $(501 \mathrm{MHz}) \delta: 7.14-7.40(\mathrm{~m}, 30 \mathrm{H}), 5.23(\mathrm{~s}, 1 \mathrm{H}), 5.13(\mathrm{~d}, J=1.7 \mathrm{~Hz}, 1 \mathrm{H}), 4.90(\mathrm{~d}, J=11.2$ $\mathrm{Hz}, 1 \mathrm{H}), 4.89(\mathrm{~d}, J=10.9 \mathrm{~Hz}, 1 \mathrm{H}), 4.80(\mathrm{~d}, J=11.7 \mathrm{~Hz}, 1 \mathrm{H}), 4.70-4.75(\mathrm{~m}, 2 \mathrm{H}), 4.57-4.69$ $(\mathrm{m}, 4 \mathrm{H}), 4.48-4.55(\mathrm{~m}, 2 \mathrm{H}), 4.36(\mathrm{~d}, J=11.6 \mathrm{~Hz}, 1 \mathrm{H}), 4.20(\mathrm{dd}, J=9.6,3.0 \mathrm{~Hz}, 1 \mathrm{H}), 4.16-$ $4.22(\mathrm{~m}, 1 \mathrm{H}), 4.12(\mathrm{~d}, J=11.7 \mathrm{~Hz}, 1 \mathrm{H}), 4.01-4.05(\mathrm{~m}, 1 \mathrm{H}), 3.97(\mathrm{td}, J=9.0,3.5 \mathrm{~Hz}, 1 \mathrm{H})$, $3.79-3.89(\mathrm{~m}, 4 \mathrm{H}), 3.60-3.77(\mathrm{~m}, 6 \mathrm{H}), 3.42-3.47(\mathrm{~m}, 1 \mathrm{H}), 3.42(\mathrm{t}, J=9.5 \mathrm{~Hz}, 1 \mathrm{H}), 3.31$ $(\mathrm{t}, J=9.3 \mathrm{~Hz}, 1 \mathrm{H}), 2.29(\mathrm{~d}, J=9.5 \mathrm{~Hz}, 1 \mathrm{H}), 2.20-2.30(\mathrm{~m}, 1 \mathrm{H}), 1.79-1.92(\mathrm{~m}, 2 \mathrm{H}), 1.67-$ $1.77(\mathrm{~m}, 1 \mathrm{H}), 1.33(\mathrm{~d}, J=6.2 \mathrm{~Hz}, 3 \mathrm{H}), 1.30(\mathrm{~d}, J=6.1 \mathrm{~Hz}, 3 \mathrm{H}), 1.25(\mathrm{~d}, J=6.2 \mathrm{~Hz}, 3 \mathrm{H}) ;{ }^{13} \mathrm{C}$ NMR $(126 \mathrm{MHz}) \delta: 138.8,138.6,138.5,138.3,138.1,137.8,128.50,128.47,128.4,128.1$, $127.84,127.78,127.6,126.9,99.2\left({ }^{1} J_{\mathrm{CH}}=170.0 \mathrm{~Hz}\right), 99.1\left({ }^{1} J_{\mathrm{CH}}=168.7 \mathrm{~Hz}\right), 99.0\left({ }^{1} J_{\mathrm{CH}}=\right.$ $170.0 \mathrm{~Hz}), 98.5\left({ }^{1} J_{\mathrm{CH}}=170.0 \mathrm{~Hz}\right), 82.2,81.1,80.6,79.9,79.2,77.9,76.8,75.5,74.9,74.7$, 74.6, 72.6, 72.5, 72.4, 71.7, 68.9, 68.2, 67.7, 66.4, 52.6, 52.5, 36.1, 33.03, 33.00, 26.9, 18.2, 18.1, 18.0; ESIHRMS Calcd for $\mathrm{C}_{65} \mathrm{H}_{76} \mathrm{Br}_{2} \mathrm{NaO}_{13}[\mathrm{M}+\mathrm{Na}]^{+}$: 1245.3550. Found 1245.3521.

\section{Methyl 2,4-Di-O-benzyl-3-O-(2-naphthylmethyl)- $\alpha$-L-rhamnopyranosyl-(1 $\rightarrow 3$ )-2,4-di-O- benzyl- $\alpha-L-r h a m n o p y r a n o s i d e ~(24 \alpha)$ and Methyl 2,4-Di-O-benzyl-3-O-(2-naphthylmethyl)- $\beta$-L- rhamnopyranosyl-(1 $\rightarrow 3)-2,4-d i-O$-benzyl- $\alpha$-L-rhamnopyrano-side $(24 \beta)$}

Method A-To a solution of 14 (17 mg, $0.039 \mathrm{mmol})$, TTBP (19 mg, $0.078 \mathrm{mmol})$, BSP (8 $\mathrm{mg}, 0.039 \mathrm{mmol})$, and activated $3 \AA$ powdered molecular sieves in $\mathrm{CH}_{2} \mathrm{Cl}_{2}(1.5 \mathrm{~mL}) \mathrm{Tf}_{2} \mathrm{O}(7.2$ $\mu \mathrm{L}, 0.043 \mathrm{mmol})$ was added at $-60{ }^{\circ} \mathrm{C}$. The reaction mixture was stirred for $5 \mathrm{~min}$ at this temperature, and solution of $\mathbf{2 3}(17 \mathrm{mg}, 0.048 \mathrm{mmol})$ in $\mathrm{CH}_{2} \mathrm{Cl}_{2}(0.6 \mathrm{~mL})$ was added dropwise. The reaction mixture was stirred for an additional $2 \mathrm{~min}$ at $-60^{\circ} \mathrm{C}$, then slowly warmed to r.t., filtered, washed (sat. aq. $\left.\mathrm{Na}_{2} \mathrm{CO}_{3}\right)$, dried $\left(\mathrm{Na}_{2} \mathrm{SO}_{4}\right)$, and concentrated. Filtration of the crude through a pad of silica gel (with ethyl acetate as an eluent) and purification by means of radial chromatography $\left(\mathrm{SiO}_{2}\right.$, hexanes to $3 / 17$ ethyl acetate/hexanes) gave $\mathbf{2 4 \alpha}(19 \mathrm{mg}, 72 \%)$ and $24 \boldsymbol{\beta}(3 \mathrm{mg}, 10 \%) . \mathbf{2 4 \alpha} \cdot[\alpha]^{23} \mathrm{D}+252.3\left(c 0.13, \mathrm{CHCl}_{3}\right) .{ }^{1} \mathrm{H}$ NMR $(500 \mathrm{MHz}) \delta: 7.79-7.87$ $(\mathrm{m}, 4 \mathrm{H}), 7.54(\mathrm{~d}, J=8.4 \mathrm{~Hz}, 1 \mathrm{H}), 7.41-7.48(\mathrm{~m}, 4 \mathrm{H}), 7.28-7.40(\mathrm{~m}, 8 \mathrm{H}), 5.10(\mathrm{~d}, J=3.3$ $\mathrm{Hz}, 1 \mathrm{H}), 5.06(\mathrm{~d}, J=10.8 \mathrm{~Hz}, 1 \mathrm{H}), 4.96(\mathrm{~d}, J=11.0 \mathrm{~Hz}, 1 \mathrm{H}), 4.82-4.87(\mathrm{~m}, 2 \mathrm{H}), 4.74(\mathrm{~d}, J$ $=12.1 \mathrm{~Hz}, 1 \mathrm{H}), 4.69(\mathrm{~s}, 1 \mathrm{H}), 4.59(\mathrm{~d}, J=10.6 \mathrm{~Hz}, 1 \mathrm{H}), 4.04(\mathrm{dd}, J=8.9,2.7 \mathrm{~Hz}, 1 \mathrm{H}), 3.92(\mathrm{t}$, $J=9.5 \mathrm{~Hz}, 1 \mathrm{H}), 3.81-3.88(\mathrm{~m}, 2 \mathrm{H}), 3.62-3.71(\mathrm{~m}, 2 \mathrm{H}), 3.55(\mathrm{~s}, 3 \mathrm{H}), 3.39$ (dd, $J=9.4,2.9$ $\mathrm{Hz}, 1 \mathrm{H}), 3.31(\mathrm{~s}, 3 \mathrm{H}), 3.13(\mathrm{t}, J=9.8 \mathrm{~Hz}, 1 \mathrm{H}), 1.35(\mathrm{~d}, J=5.5 \mathrm{~Hz}, 3 \mathrm{H}), 1.15(\mathrm{~d}, J=6.1 \mathrm{~Hz}$, $3 \mathrm{H}) ;{ }^{13} \mathrm{C}$ NMR (126 MHz) $\delta$ : 138.4, 138.0, 135.6, 133.3, 133.0, 128.4, 128.1, 128.0, 127.8, $127.73,127.71,127.67,127.0,126.2,126.0,125.9,98.8\left({ }^{1} J_{\mathrm{CH}}=168.7 \mathrm{~Hz}\right), 93.5\left({ }^{1} J_{\mathrm{CH}}=167.4\right.$ $\mathrm{Hz}), 82.6,79.8,75.64,75.56,75.4,74.3,72.8,68.3,68.0,66.4,59.5,54.7,18.5,18.1$; FABHRMS Calcd for $\mathrm{C}_{39} \mathrm{H}_{45} \mathrm{~N}_{3} \mathrm{NaO}_{8}[\mathrm{M}+\mathrm{Na}]^{+}:$706.3104. Found 706.3097. 24及. $[\alpha]^{23} \mathrm{D}$ $+12.2\left(c 0.18, \mathrm{CHCl}_{3}\right) .{ }^{1} \mathrm{H}$ NMR $(400 \mathrm{MHz}) \delta: 7.81-7.89(\mathrm{~m}, 4 \mathrm{H}), 7.56(\mathrm{dd}, J=8.3,1.5 \mathrm{~Hz}$, $1 \mathrm{H}), 7.44-7.51(\mathrm{~m}, 2 \mathrm{H}), 7.39-7.43(\mathrm{~m}, 4 \mathrm{H}), 7.27-7.37(\mathrm{~m}, 6 \mathrm{H}), 5.1(\mathrm{~d}, J=11.0 \mathrm{~Hz}, 1 \mathrm{H})$, $4.96-5.02(\mathrm{~m}, 2 \mathrm{H}), 4.84(\mathrm{~d}, J=12.3 \mathrm{~Hz}, 1 \mathrm{H}), 4.74(\mathrm{~d}, J=12.3 \mathrm{~Hz}, 1 \mathrm{H}), 4.55-4.65(\mathrm{~m}, 3 \mathrm{H})$, $4.03(\mathrm{dd}, J=8.9,3.2 \mathrm{~Hz}, 1 \mathrm{H}), 3.82(\mathrm{dd}, J=3.1,1.8 \mathrm{~Hz}, 1 \mathrm{H}), 3.69(\mathrm{~s}, 3 \mathrm{H}), 3.59-3.68(\mathrm{~m}, 2 \mathrm{H})$, $3.45(\mathrm{t}, J=9.0 \mathrm{~Hz}, 1 \mathrm{H}), 3.29(\mathrm{~s}, 3 \mathrm{H}), 3.11-3.22(\mathrm{~m}, 3 \mathrm{H}), 1.36(\mathrm{~d}, J=5.9 \mathrm{~Hz}, 3 \mathrm{H}), 1.29(\mathrm{~d}$, $J=5.4 \mathrm{~Hz}, 3 \mathrm{H}) ;{ }^{13} \mathrm{C}$ NMR $(101 \mathrm{MHz}) \delta: 138.8,138.5,135.5,133.3,133.1,128.4,128.24$, $128.18,128.0,127.9,127.8,127.7,127.5,127.1,126.3,126.1,126.0,103.7\left({ }^{1} J_{\mathrm{CH}}=160.9 \mathrm{~Hz}\right)$, $99.7\left({ }^{1} J_{\mathrm{CH}}=168.3 \mathrm{~Hz}\right), 84.9,82.8,80.8,79.1,78.4,75.5,74.8,73.5,70.3,67.9,67.7,60.8$, 54.5, 18.6, 18.0; FABHRMS Calcd for $\mathrm{C}_{39} \mathrm{H}_{45} \mathrm{~N}_{3} \mathrm{NaO}_{8}[\mathrm{M}+\mathrm{Na}]^{+}$: 706.3104. Found 706.3080.

Method B-To a solution of $\mathbf{1 4}(18 \mathrm{mg}, 0.042 \mathrm{mmol})$, TTBP (21 mg, $0.085 \mathrm{mmol})$, BSP ( 9 $\mathrm{mg}, 0.042 \mathrm{mmol})$, and activated $3 \AA$ powdered molecular sieves in propionitrile $(1.5 \mathrm{~mL})$ $\mathrm{Tf}_{2} \mathrm{O}(7.9 \mu \mathrm{L}, 0.047 \mathrm{mmol})$ was added at $-60^{\circ} \mathrm{C}$. The reaction mixture was stirred for $5 \mathrm{~min}$ 
at this temperature, and solution of $\mathbf{2 3}(19 \mathrm{mg}, 0.052 \mathrm{mmol})$ in propionitrile $(0.6 \mathrm{~mL})$ was added dropwise. The reaction mixture was stirred for an additional $2 \mathrm{~min}$ at $-60^{\circ} \mathrm{C}$, then warmed to r.t., filtered, diluted with $\mathrm{CH}_{2} \mathrm{Cl}_{2}$, washed (sat. aq. $\left.\mathrm{Na}_{2} \mathrm{CO}_{3}\right)$, dried $\left(\mathrm{Na}_{2} \mathrm{SO}_{4}\right)$, and concentrated. Filtration of the crude through a pad of silica gel (with ethyl acetate as an eluent) and purification by radial chromatography $\left(\mathrm{SiO}_{2}\right.$, hexanes to $3 / 17$ ethyl acetate/hexanes) gave $\mathbf{2 4 \alpha}(10.3 \mathrm{mg}, 36 \%)$ and $\mathbf{2 4 \beta}(9.7 \mathrm{mg}, 34 \%)$.

Method C-A solution of $\mathbf{1 4}(27 \mathrm{mg}, 0.062 \mathrm{mmol}), \mathbf{2 3}(18 \mathrm{mg}, 0.050 \mathrm{mmol})$ and activated 3 $\AA$ powdered molecular sieves in propionitrile $(1 \mathrm{~mL})$ was stirred for $10 \mathrm{~min}$ at r.t., then cooled to $-60{ }^{\circ} \mathrm{C}$ and $\mathrm{N}$-iodosuccinimide $(14 \mathrm{mg}, 0.062 \mathrm{mmol})$, followed by TfOH $(1.1 \mu \mathrm{L}, 0.012$ mmol) were added. The reaction mixture was stirred for $8 \mathrm{~h}$ at -60 to $-65^{\circ} \mathrm{C}$, then quenched with $\mathrm{Et}_{3} \mathrm{~N}\left(9 \mu \mathrm{L}, 0.062 \mathrm{mmol}\right.$ ), filtered, diluted with $\mathrm{CH}_{2} \mathrm{Cl}_{2}$, washed (sat. aq. $\mathrm{Na}_{2} \mathrm{~S}_{2} \mathrm{O}_{3}$, sat. aq. $\left.\mathrm{Na}_{2} \mathrm{CO}_{3}\right)$, dried $\left(\mathrm{Na}_{2} \mathrm{SO}_{4}\right)$, and concentrated. Filtration of the crude through a pad of silica gel (with ethyl acetate as an eluent) and purification by radial chromatography $\left(\mathrm{SiO}_{2}\right.$, hexanes to $3 / 17$ ethyl acetate/hexanes) gave $\mathbf{2 4} \boldsymbol{\alpha}(8 \mathrm{mg}, 23 \%)$ and $\mathbf{2 4 \beta}(25 \mathrm{mg}, 70 \%)$.

\section{4,5-Dibromopentyl 4-Azido-4-deoxy-2-O-methyl-3-O-(2-naphthylmethyl)- $\alpha-D-$ quinovopyranosyl-( $\rightarrow 3$ )-2,4-di-O-benzyl- $\alpha$-L-rhamnopyranosyl-(1 $\rightarrow 3)-2,4-d i-O$-benzyl- $\alpha-L-$ rhamnopyranosyl-(1 $\rightarrow 2)-3,4-d i-O-$-benzyl- $\alpha$-L-rhamnopyranoside $(25 \alpha)$ and $4,5-$ Dibromopentyl 4-Azido-4-deoxy-2-O-methyl-3-O-(2-naphthylmethyl)- $\beta$-D-quinovopyranosyl- $(1 \rightarrow 3)-2,4-d i-O$-benzyl- $\alpha$-L-rhamnopyranosyl-(1 $\rightarrow 3)$-2,4-di-O-benzyl- $\alpha$-L-rhamnopyranosyl- $(1 \rightarrow 2)-3,4-d i-O-b e n z y l-\alpha-L-r h a m n o p y r a n o s i d e ~(25 \beta)$}

A solution of $\mathbf{2 2}(118 \mathrm{mg}, 0.096 \mathrm{mmol}), \mathbf{1 4}(50 \mathrm{mg}, 0.115 \mathrm{mmol})$, and activated $3 \AA$ powdered molecular sieves in propionitrile $(2.4 \mathrm{~mL})$ was stirred for $10 \mathrm{~min}$ at r.t., then cooled to $-60{ }^{\circ} \mathrm{C}$ and $N$-iodosuccinimide ( $26 \mathrm{mg}, 0.116 \mathrm{mmol})$, followed by TfOH $(1.7 \mu \mathrm{L}, 0.019 \mathrm{mmol})$ were added. The reaction mixture was stirred for $9 \mathrm{~h}$ at -60 to $-65^{\circ} \mathrm{C}$, then quenched with $\mathrm{Et}_{3} \mathrm{~N}$ (16 $\mu \mathrm{L}, 0.115 \mathrm{mmol}$ ), filtered, diluted with $\mathrm{CH}_{2} \mathrm{Cl}_{2}$, washed (sat. aq. $\mathrm{Na}_{2} \mathrm{~S}_{2} \mathrm{O}_{3}$, sat. aq. $\mathrm{Na}_{2} \mathrm{CO}_{3}$ ), dried $\left(\mathrm{Na}_{2} \mathrm{SO}_{4}\right)$, and concentrated. Filtration of the crude through a pad of silica gel (with ethyl acetate as an eluent), purification by radial chromatography $\left(\mathrm{SiO}_{2}\right.$, hexanes to $3 / 17$ ethyl acetate/hexanes) gave $\mathbf{2 5} \boldsymbol{\alpha}$ as a mixture of two diastereomers in the dibromopentyl chain (32 $\mathrm{mg}, 21 \%)$ and $\mathbf{2 5 \beta}$ of two diastereomers in the dibromopentyl chain $(105 \mathrm{mg}, 71 \%) . \mathbf{2 5 \alpha} .{ }^{1} \mathrm{H}$ NMR (500 MHz): $7.74-7.87(\mathrm{~m}, 4 \mathrm{H}), 7.51(\mathrm{dd}, J=8.4,1.7 \mathrm{~Hz}, 1 \mathrm{H}), 7.42-7.47$ (m, 2H), $7.12-7.35(\mathrm{~m}, 30 \mathrm{H}), 5.21(\mathrm{~s}, 1 \mathrm{H}), 5.10(\mathrm{~d}, J=1.5 \mathrm{~Hz}, 1 \mathrm{H}), 5.00-5.04(\mathrm{~m}, 2 \mathrm{H}), 4.91(\mathrm{~d}, J=$ $11.0 \mathrm{~Hz}, 1 \mathrm{H}), 4.85(\mathrm{~d}, J=10.8 \mathrm{~Hz}, 1 \mathrm{H}), 4.82(\mathrm{~d}, J=10.8 \mathrm{~Hz}, 1 \mathrm{H}), 4.75(\mathrm{~d}, J=11.7 \mathrm{~Hz}, 1 \mathrm{H})$, $4.70(\mathrm{~d}, J=1.5 \mathrm{~Hz}, 1 \mathrm{H}), 4.62-4.67(\mathrm{~m}, 2 \mathrm{H}), 4.55-4.61(\mathrm{~m}, 3 \mathrm{H}), 4.51-4.55(\mathrm{~m}, 2 \mathrm{H}), 4.49$ (s, $1 \mathrm{H}), 4.40(\mathrm{~d}, J=11.6 \mathrm{~Hz}, 1 \mathrm{H}), 4.11-4.21(\mathrm{~m}, 3 \mathrm{H}), 3.99-4.01(\mathrm{~m}, 1 \mathrm{H}), 3.76-3.90(\mathrm{~m}$, $8 \mathrm{H}), 3.55-3.71(\mathrm{~m}, 5 \mathrm{H}), 3.37-3.46(\mathrm{~m}, 5 \mathrm{H}), 3.34(\mathrm{dd}, J=9.4,3.5 \mathrm{~Hz}, 1 \mathrm{H}), 3.10(\mathrm{t}, J=9.8$ $\mathrm{Hz}, 1 \mathrm{H}), 2.18-2.27(\mathrm{~m}, 1 \mathrm{H}), 1.77-1.89(\mathrm{~m}, 2 \mathrm{H}), 1.63-1.74(\mathrm{~m}, 1 \mathrm{H}), 1.282(\mathrm{~d}, J=6.2 \mathrm{~Hz}$, $3 \mathrm{H}), 1.278(\mathrm{~d}, J=6.1 \mathrm{~Hz}, 3 \mathrm{H}), 1.24(\mathrm{~d}, J=6.2 \mathrm{~Hz}, 3 \mathrm{H}), 1.06(\mathrm{~d}, J=6.2 \mathrm{~Hz}, 3 \mathrm{H}) ;{ }^{13} \mathrm{C} \mathrm{NMR}$ (126 MHz) $\delta$ : 138.6, 138.4, 138.3, 138.0, 135.6, 133.3, 133.0, 128.47, 128.42, 128.34, 128.26. $128.12,128.09,128.0,127.8,127.68,127.65,127.60,127.56,127.5,127.0,126.2,126.0$, $125.9,99.5\left({ }^{1} J_{\mathrm{CH}}=169.9 \mathrm{~Hz}\right), 99.1\left({ }^{1} J_{\mathrm{CH}}=169.2 \mathrm{~Hz}\right), 99.0\left({ }^{1} J_{\mathrm{CH}}=169.2 \mathrm{~Hz}\right), 98.9\left({ }^{1} J_{\mathrm{CH}}=\right.$ $168.5 \mathrm{~Hz}), 93.1\left({ }^{1} J_{\mathrm{CH}}=165.3 \mathrm{~Hz}\right), 82.6,80.8,80.5,79.9,79.7,77.6,75.52,75.49,75.4,75.2$, 74.7, 74.5, 72.6, 72.4, 72.3, 68.8, 68.2, 68.1, 66.3, 59.1, 52.6, 52.5, 36.1, 33.01, 32.97, 26.8, 18.5, 18.10, 18.05; ESIHRMS Calcd for $\mathrm{C}_{83} \mathrm{H}_{95} \mathrm{~N}_{3} \mathrm{NaO}_{16} \mathrm{Br}_{2}[\mathrm{M}+\mathrm{Na}]^{+}:$1570.4977. Found 1570.4920. 25及. ${ }^{1} \mathrm{H}$ NMR $(501 \mathrm{MHz}) \delta: 7.82-7.87(\mathrm{~m}, 4 \mathrm{H}), 7.53-7.57(\mathrm{~m}, 1 \mathrm{H}), 7.44-7.50$ $(\mathrm{m}, 2 \mathrm{H}), 7.38-7.42(\mathrm{~m}, 2 \mathrm{H}), 7.16-7.37(\mathrm{~m}, 28 \mathrm{H}), 5.12(\mathrm{~s}, 1 \mathrm{H}), 5.09(\mathrm{~s}, 1 \mathrm{H}), 5.06(\mathrm{~d}, J=10.8$ $\mathrm{Hz}, 1 \mathrm{H}), 4.95-5.00(\mathrm{~m}, 2 \mathrm{H}), 4.87(\mathrm{~d}, J=10.8 \mathrm{~Hz}, 1 \mathrm{H}), 4.66-4.72(\mathrm{~m}, 2 \mathrm{H}), 4.54-4.66(\mathrm{~m}$, $7 \mathrm{H}), 4.44-4.50(\mathrm{~m}, 3 \mathrm{H}), 4.10-4.21(\mathrm{~m}, 3 \mathrm{H}), 3.99-4.01(\mathrm{~m}, 1 \mathrm{H}), 3.88-3.91(\mathrm{~m}, 1 \mathrm{H}), 3.81$ $-3.87(\mathrm{~m}, 4 \mathrm{H}), 3.75-3.80(\mathrm{~m}, 1 \mathrm{H}), 3.66-3.69(\mathrm{~m}, 4 \mathrm{H}), 3.59-3.71(\mathrm{~m}, 3 \mathrm{H}), 3.55(\mathrm{t}, J=9.1$ $\mathrm{Hz}, 1 \mathrm{H}), 3.35-3.45(\mathrm{~m}, 3 \mathrm{H}), 3.16(\mathrm{t}, J=8.4 \mathrm{~Hz}, 1 \mathrm{H}), 3.08(\mathrm{t}, J=9.4 \mathrm{~Hz}, 1 \mathrm{H}), 3.00-3.08(\mathrm{~m}$, 1H), $2.17-2.28(\mathrm{~m}, 1 \mathrm{H}), 1.77-1.89(\mathrm{~m}, 2 \mathrm{H}), 1.64-1.74(\mathrm{~m}, 1 \mathrm{H}), 1.283(\mathrm{~d}, J=6.1 \mathrm{~Hz}, 3 \mathrm{H})$, 
$1.279(\mathrm{~d}, J=6.1 \mathrm{~Hz}, 3 \mathrm{H}), 1.26(\mathrm{~d}, J=6.2 \mathrm{~Hz}, 3 \mathrm{H}), 1.12(\mathrm{~d}, J=5.5 \mathrm{~Hz}, 3 \mathrm{H}) ;{ }^{13} \mathrm{C}$ NMR $(126$ MHz) $\delta: 138.8,138.5,138.3,138.2,135.5,133.4,133.1,128.5,128.33,128.28,128.2,128.13$, 128.07, 128.0, 127.73, 127.69, 127.66, 127.60, 127.58, 127.42, 127.39, 127.1, 126.3, 126.1, $126.0,103.6\left({ }^{1} J_{\mathrm{CH}}=161.2 \mathrm{~Hz}\right), 100.3\left({ }^{1} J_{\mathrm{CH}}=168.7 \mathrm{~Hz}\right), 99.0\left({ }^{1} J_{\mathrm{CH}}=170.0 \mathrm{~Hz}\right), 98.9$ $\left({ }^{1} J_{\mathrm{CH}}=169.2 \mathrm{~Hz}\right), 84.9,82.8,81.0,80.61,80.55,80.0,79.4,78.6,78.1,75.49,75.46,74.84$, 74.76, 74.7, 73.4, 72.5, 72.2, 70.3, 68.7, 68.4, 68.1, 67.8, 66.3, 60.8, 52.6, 52.5, 36.1, 33.02, 32.99, 26.8, 18.5, 18.1, 18.0; ESIHRMS Calcd for $\mathrm{C}_{83} \mathrm{H}_{95} \mathrm{~N}_{3} \mathrm{NaO}_{16} \mathrm{Br}_{2}[\mathrm{M}+\mathrm{Na}]^{+}: 1570.4977$. Found 1570.4930 .

\section{n-Pentenyl 4-Azido-4-deoxy-2-O-methyl-3-O-(2-naphthylmethyl)- $\beta$-D-quinovo-pyranosyl- $(1 \rightarrow 3)-2,4-d i-O$-benzyl- $\alpha$-L-rhamnopyranosyl-(1 $\rightarrow 3)-2,4-d i-O$-benzyl- $\alpha$-L-rhamnopyranosyl- $(1 \rightarrow 2)-3,4-d i-O$-benzyl-a-L-rhamnopyranoside (26)}

A mixture of $\mathbf{2 5 \beta}$ ( $98 \mathrm{mg}, 0.063 \mathrm{mmol}$ ), NaI (190 mg, $1.268 \mathrm{mmol})$, and 2-butanone (6 mL) was heated to reflux for $5 \mathrm{~h}$. The reaction mixture was cooled to r.t., diluted with ethyl acetate, washed (sat. aq. $\mathrm{Na}_{2} \mathrm{~S}_{2} \mathrm{O}_{3}$,), dried $\left(\mathrm{Na}_{2} \mathrm{SO}_{4}\right)$, and concentrated. Filtration of the crude through a pad of silica gel (with ethyl acetate as an eluent), purification by radial chromatography $\left(\mathrm{SiO}_{2}\right.$, hexanes to $1 / 9$ ethyl acetate/hexanes) gave $26(82 \mathrm{mg}, 94 \%)$. $[\alpha]^{15} \mathrm{D}+10.0(c 0.23$, $\left.\mathrm{CHCl}_{3}\right) .{ }^{1} \mathrm{H}$ NMR $(501 \mathrm{MHz}) \delta: 7.83-7.91(\mathrm{~m}, 4 \mathrm{H}), 7.56(\mathrm{dd}, J=8.5,1.4 \mathrm{~Hz}, 1 \mathrm{H}), 7.45-$ $7.51(\mathrm{~m}, 2 \mathrm{H}), 7.15-7.43(\mathrm{~m}, 30 \mathrm{H}), 5.76-5.85(\mathrm{~m}, 1 \mathrm{H}), 5.13$ (br. s., $1 \mathrm{H}), 5.11(\mathrm{~d}, J=1.5 \mathrm{~Hz}$, $1 \mathrm{H}), 5.08(\mathrm{~d}, J=11.0 \mathrm{~Hz}, 1 \mathrm{H}), 5.01-5.06(\mathrm{~m}, 1 \mathrm{H}), 4.97-5.01(\mathrm{~m}, 3 \mathrm{H}), 4.88(\mathrm{~d}, J=10.8 \mathrm{~Hz}$, $1 \mathrm{H}), 4.59-4.73(\mathrm{~m}, 8 \mathrm{H}), 4.57(\mathrm{~d}, J=11.2 \mathrm{~Hz}, 1 \mathrm{H}), 4.44-4.51(\mathrm{~m}, 3 \mathrm{H}), 4.11-4.17(\mathrm{~m}, 2 \mathrm{H})$, $4.02-4.04(\mathrm{~m}, 1 \mathrm{H}), 3.90(\mathrm{dd}, J=2.6,1.7 \mathrm{~Hz}, 1 \mathrm{H}), 3.82-3.87(\mathrm{~m}, 3 \mathrm{H}), 3.77-3.82(\mathrm{~m}, 1 \mathrm{H})$, $3.62-3.71(\mathrm{~m}, 6 \mathrm{H}), 3.56(\mathrm{t}, J=9.4 \mathrm{~Hz}, 1 \mathrm{H}), 3.35-3.45(\mathrm{~m}, 3 \mathrm{H}), 3.17(\mathrm{dd}, J=8.9,8.0 \mathrm{~Hz}$, $1 \mathrm{H}), 3.09(\mathrm{t}, J=9.5 \mathrm{~Hz}, 1 \mathrm{H}), 3.01-3.09(\mathrm{~m}, 1 \mathrm{H}), 2.06-2.14(\mathrm{~m}, 2 \mathrm{H}), 1.62-1.69(\mathrm{~m}, 2 \mathrm{H})$, $1.30(\mathrm{~d}, J=6.2 \mathrm{~Hz}, 3 \mathrm{H}), 1.29(\mathrm{~d}, J=6.1 \mathrm{~Hz}, 3 \mathrm{H}), 1.27(\mathrm{~d}, J=6.2 \mathrm{~Hz}, 3 \mathrm{H}), 1.12(\mathrm{~d}, J=5.9 \mathrm{~Hz}$, $3 \mathrm{H}) ;{ }^{13} \mathrm{C}$ NMR (126 MHz) $\delta: 138.7,138.4,138.33,138.31,138.2,138.0,135.5,133.3,133.1$, $128.4,128.3,128.2,128.14,128.09,128.05,128.03,127.98,127.7,127.64,127.57,127.53$, $127.50,127.4,127.1,126.2,126.1,125.9,114.9,103.5\left({ }^{1} \mathrm{~J}_{\mathrm{CH}}=161.2 \mathrm{~Hz}\right), 100.3\left({ }^{1} \mathrm{~J}_{\mathrm{CH}}=168.7\right.$ $\mathrm{Hz}), 98.9\left({ }^{1} \mathrm{~J}_{\mathrm{CH}}=168.7 \mathrm{~Hz}\right), 84.8,82.7,80.9,80.58,80.55,80.1,79.3,78.5,78.0,75.5,75.4$, 74.7, 74.6, 73.3, 72.4, 72.1, 70.2, 68.6, 68.4, 67.9, 67.7, 66.7, 60.8, 30.3, 28.6, 18.4, 18.02, 17.98, 17.95; ESIHRMS Calcd for $\mathrm{C}_{83} \mathrm{H}_{95} \mathrm{~N}_{3} \mathrm{NaO}_{16}[\mathrm{M}+\mathrm{Na}]^{+}:$1412.6610. Found 1412.6560.

\section{$n$-Pentenyl 4-Azido-4-deoxy-2-O-methyl- $\beta$-D-quinovopyranosyl-(1 $\rightarrow 3)-2,4-d i-O$-benzyl- $\alpha-L-$ rhamnopyranosyl-(1 $\rightarrow 3)$-2,4-di-O-benzyl- $\alpha$-L-rhamnopyranosyl-(1 $\rightarrow 2)-3,4-d i-O-b e n z y l-\alpha-L-$ rhamnopyranoside (27) and $n$-Pentenyl 4-Azido-3-O-benzyl-4-deoxy-2-O-methyl- $\beta$-D- quinovopyranosyl-(1 $\rightarrow 3)-2,4-d i-O$-benzyl- $\alpha$-L-rhamno-pyranosyl-(1 $\rightarrow 3)-2,4-d i-O-b e n z y l-\alpha-L-$

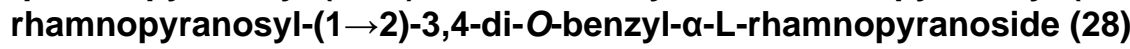

To a solution of $26(122 \mathrm{mg}, 0.088 \mathrm{mmol})$ in $\mathrm{MeOH} / \mathrm{CH}_{2} \mathrm{Cl}_{2}(0.7 \mathrm{~mL} / 2.1 \mathrm{~mL}) \mathrm{DDQ}(60 \mathrm{mg}$, $0.26 \mathrm{mmol}$ ) was added at $0{ }^{\circ} \mathrm{C}$. After $30 \mathrm{~min}$, the reaction mixture was warmed to r. t. and further stirred for $5 \mathrm{~h}$ before it was diluted with $\mathrm{CH}_{2} \mathrm{Cl}_{2}$ and quenched with sat. aq. $\mathrm{Na}_{2} \mathrm{CO}_{3}$. The organic phase was separated, washed (sat. aq. $\left.\mathrm{Na}_{2} \mathrm{CO}_{3}\right)$, dried $\left(\mathrm{Na}_{2} \mathrm{SO}_{4}\right)$, and concentrated. Filtration of the crude through a pad of silica gel (with ethyl acetate as an eluent), purification by radial chromatography $\left(\mathrm{SiO}_{2}\right.$, hexanes to $1 / 9$ ethyl acetate/hexanes) gave 27 (74 $\mathrm{mg}, 67 \%$ ). $[\alpha]^{15} \mathrm{D}-11.6\left(c 0.76, \mathrm{CHCl}_{3}\right) .{ }^{1} \mathrm{H}$ NMR $(501 \mathrm{MHz}) \delta: 7.13-7.39(\mathrm{~m}, 30 \mathrm{H}), 5.74-5.85(\mathrm{~m}$, $1 \mathrm{H}), 5.11$ (br. s., $1 \mathrm{H}), 5.10(\mathrm{~d}, J=1.7 \mathrm{~Hz}, 1 \mathrm{H}), 5.02(\mathrm{dq}, J=17.2,1.5 \mathrm{~Hz}, 1 \mathrm{H}), 4.95-4.99(\mathrm{~m}$, $1 \mathrm{H}), 4.88(\mathrm{t}, J=10.5 \mathrm{~Hz}, 2 \mathrm{H}), 4.70(\mathrm{~d}, J=11.4 \mathrm{~Hz}, 1 \mathrm{H}), 4.65-4.69(\mathrm{~m}, 2 \mathrm{H}), 4.54-4.63(\mathrm{~m}$, $6 \mathrm{H}), 4.48(\mathrm{~d}, J=11.9 \mathrm{~Hz}, 1 \mathrm{H}), 4.39-4.44(\mathrm{~m}, 2 \mathrm{H}), 4.12(\mathrm{ddd}, J=12.2,9.4,3.0 \mathrm{~Hz}, 1 \mathrm{H}), 4.00$ $-4.02(\mathrm{~m}, 1 \mathrm{H}), 3.87(\mathrm{dd}, J=2.8,1.7 \mathrm{~Hz}, 1 \mathrm{H}), 3.81-3.86(\mathrm{~m}, 3 \mathrm{H}), 3.76-3.82(\mathrm{~m}, 1 \mathrm{H}), 3.60$ $-3.69(\mathrm{~m}, 6 \mathrm{H}), 3.54(\mathrm{t}, J=9.0 \mathrm{~Hz}, 1 \mathrm{H}), 3.47(\mathrm{td}, J=9.1,2.1 \mathrm{~Hz}, 1 \mathrm{H}), 3.41(\mathrm{t}, J=9.5 \mathrm{~Hz}, 1 \mathrm{H})$, $3.34-3.39(\mathrm{~m}, 1 \mathrm{H}), 3.01-3.09(\mathrm{~m}, 1 \mathrm{H}), 3.01(\mathrm{t}, J=9.5 \mathrm{~Hz}, 1 \mathrm{H}), 2.97(\mathrm{dd}, J=9.2,7.9 \mathrm{~Hz}$, $1 \mathrm{H}), 2.66(\mathrm{~d}, J=2.6 \mathrm{~Hz}, 1 \mathrm{H}), 2.06-2.13(\mathrm{~m}, 2 \mathrm{H}), 1.60-1.69(\mathrm{~m}, 2 \mathrm{H}), 1.27-1.29(\mathrm{~m}, 6 \mathrm{H})$, $1.26(\mathrm{~d}, J=6.4 \mathrm{~Hz}, 3 \mathrm{H}), 1.11(\mathrm{~d}, J=5.7 \mathrm{~Hz}, 3 \mathrm{H}) ;{ }^{13} \mathrm{C}$ NMR $(126 \mathrm{MHz}) \delta: 138.7,138.54$, 
$138.47,138.4,138.2,138.1,128.5,128.4,128.3,128.2,128.1,128.0,127.74,127.68,127.62$, 127.56, 127.41, 127.38, 115.0, $103.4\left({ }^{1} J_{\mathrm{CH}}=161.2 \mathrm{~Hz}\right), 100.2\left({ }^{1} J_{\mathrm{CH}}=166.2 \mathrm{~Hz}\right), 99.0$

$\left({ }^{1} J_{\mathrm{CH}}=168.7 \mathrm{~Hz}\right), 84.0,81.1,80.62,80.59,80.1,79.4,78.2,78.1,75.5,75.2,74.8,74.7,73.4$, 72.5, 72.1, 70.5, 68.6, 68.4, 67.9, 67.4, 66.8, 61.0, 30.3, 28.7, 18.3, 18.1, 18.02, 17.99;

ESIHRMS Calcd for $\mathrm{C}_{72} \mathrm{H}_{87} \mathrm{~N}_{3} \mathrm{NaO}_{16}[\mathrm{M}+\mathrm{Na}]^{+}$: 1272.5984 . Found 1272.5943. Further elution of with ethyl acetate gave a mixture of the debenzylated byproducts, which was dissolved in DMF $(2 \mathrm{~mL})$. Benzyl bromide $(60 \mu \mathrm{L}, 0.50 \mathrm{mmol})$ was then added, followed by $\mathrm{NaH}(60 \%$ in mineral oil, $20 \mathrm{mg}, 0.50 \mathrm{mmol})$ and the reaction mixture was stirred overnight, then diluted with ethyl acetate, washed (brine, water), dried $\left(\mathrm{Na}_{2} \mathrm{SO}_{4}\right)$, and concentrated.

Purification by radial chromatography $\left(\mathrm{SiO}_{2}\right.$, hexanes to 3/17 ethyl acetate/hexanes) gave $\mathbf{2 8}$ (26 mg, 22\%, 2 steps). $[\alpha]^{14} \mathrm{D}+2.4\left(c 1.08, \mathrm{CHCl}_{3}\right) .{ }^{1} \mathrm{H}$ NMR (501 MHz): $7.12-7.45$ (m, $35 \mathrm{H}), 5.75-5.85(\mathrm{~m}, 1 \mathrm{H}), 5.08-5.14(\mathrm{~m}, 2 \mathrm{H}), 5.02(\mathrm{dq}, J=17.2,1.7 \mathrm{~Hz}, 1 \mathrm{H}), 4.96-4.99$ $(\mathrm{m}, 2 \mathrm{H}), 4.90(\mathrm{~d}, J=10.7 \mathrm{~Hz}, 1 \mathrm{H}), 4.87(\mathrm{~d}, J=11.0 \mathrm{~Hz}, 1 \mathrm{H}), 4.81(\mathrm{~d}, J=10.6 \mathrm{~Hz}, 1 \mathrm{H}), 4.65$ $-4.72(\mathrm{~m}, 3 \mathrm{H}), 4.54-4.64(\mathrm{~m}, 6 \mathrm{H}), 4.44-4.50(\mathrm{~m}, 3 \mathrm{H}), 4.13(\mathrm{td}, J=9.5,3.0 \mathrm{~Hz}, 2 \mathrm{H}), 4.01$ - $4.02(\mathrm{~m}, 1 \mathrm{H}), 3.89(\mathrm{dd}, J=2.8,1.7 \mathrm{~Hz}, 1 \mathrm{H}), 3.76-3.86(\mathrm{~m}, 4 \mathrm{H}), 3.61-3.70(\mathrm{~m}, 6 \mathrm{H}), 3.55$ $(\mathrm{t}, J=9.5 \mathrm{~Hz}, 1 \mathrm{H}), 3.42(\mathrm{t}, J=9.5 \mathrm{~Hz}, 1 \mathrm{H}), 3.31-3.39(\mathrm{~m}, 2 \mathrm{H}), 3.13(\mathrm{dd}, J=9.1,8.0 \mathrm{~Hz}, 1 \mathrm{H})$, $2.95-3.07(\mathrm{~m}, 2 \mathrm{H}), 2.06-2.13(\mathrm{~m}, 2 \mathrm{H}), 1.61-1.69(\mathrm{~m}, 2 \mathrm{H}), 1.284(\mathrm{~d}, J=6.2 \mathrm{~Hz}, 3 \mathrm{H}), 1.279$ $(\mathrm{d}, J=6.2 \mathrm{~Hz}, 3 \mathrm{H}), 1.26(\mathrm{~d}, J=6.2 \mathrm{~Hz}, 3 \mathrm{H}), 1.11(\mathrm{~d}, J=5.7 \mathrm{~Hz}, 3 \mathrm{H}) ;{ }^{13} \mathrm{C}$ NMR $(126 \mathrm{MHz})$ $\delta: 138.80,138.78,138.5,138.40,138.38,138.2,138.1,138.0,128.44,128.40,128.32,128.26$, $128.12,128.08,127.9,127.71,127.68,127.60,127.56,127.5,127.40,127.37,114.9,103.6$ $\left({ }^{1} J_{\mathrm{CH}}=161.2 \mathrm{~Hz}\right), 100.3\left({ }^{1} J_{\mathrm{CH}}=173.7 \mathrm{~Hz}\right), 99.1\left({ }^{1} J_{\mathrm{CH}}=167.4 \mathrm{~Hz}\right), 99.0\left({ }^{1} J_{\mathrm{CH}}=167.4 \mathrm{~Hz}\right)$, 84.8, 82.7, 81.0, 80.64, 80.63, 80.1, 79.4, 78.6, 78.1, 75.49, 75.45, 74.8, 74.6, 73.4, 72.5, 72.2, 70.3, 68.7, 68.4, 68.0, 67.7, 66.8, 60.8, 30.3, 28.7, 18.5, 18.1, 18.02, 17.99; ESIHRMS Calcd for $\mathrm{C}_{79} \mathrm{H}_{93} \mathrm{~N}_{3} \mathrm{NaO}_{16}[\mathrm{M}+\mathrm{Na}]^{+}$: 1362.6454 . Found 1362.6404.

\section{n-Pentenyl 4-deoxy-4-(3-hydroxy-3-methylbutanamido)-2-O-methyl- $\beta$-D-quinovo-pyranosyl- $(1 \rightarrow 3)$ - $\alpha$-L-rhamnopyranosyl-(1 $\rightarrow 3$ )- $\alpha$-L-rhamnopyranosyl-(1 $\rightarrow 2)$ - $\alpha$-L-rhamnopyranoside (2)}

Ammonia was condensed at $-78{ }^{\circ} \mathrm{C}$ in a reaction vessel, containing a solution of $\mathbf{2 7}(26 \mathrm{mg}$, $0.021 \mathrm{mmol})$ and $28(9 \mathrm{mg}, 0.007 \mathrm{mmol})$ in THF (6 mL), until a total volume of about $20 \mathrm{~mL}$ was reached. Sodium ( $45 \mathrm{mg}, 1.96 \mathrm{mmol}$ ) was then added in small pieces, affording a solution of dark blue color. The reaction mixture was stirred for $1 \mathrm{~h}$ at this temperature and then quenched by the addition of the methanol. The reaction mixture was warmed to r.t., in order to evaporate the ammonia, and then concentrated. Purification by column chromatography (eluting first with $\mathrm{CHCl}_{3}$ to remove most of the byproducts, and then with $1 / 4 \mathrm{MeOH} / \mathrm{CHCl}_{3}$, and finally $\mathrm{MeOH})$ gave a crude product, which was dissolved in $(i-\mathrm{Pr})_{2} \mathrm{EtN}$ and concentrated (2 times). DMF ( $2 \mathrm{~mL}$ ) was then added, followed by 3-hydroxy-3-methylbutyric acid ( $5 \mathrm{mg}, 0.042$ $\mathrm{mmol})$, HATU $(16 \mathrm{mg}, 0.042 \mathrm{mmol})$, and $(i-\operatorname{Pr})_{2} \operatorname{EtN}(28 \mu \mathrm{L}, 0.16 \mathrm{mmol})$. The reaction mixture was stirred overnight and then concentrated. Purification by column chromatography $\left(\mathrm{SiO}_{2}\right.$, $\mathrm{CHCl}_{3}$ to $\left.9 / 31 \mathrm{MeOH} / \mathrm{CHCl}_{3}\right)$, followed by purification by preparative TLC $(9 / 31 \mathrm{MeOH} /$ $\left.\mathrm{CHCl}_{3}\right)$ and further column chromatography $\left(\mathrm{SiO}_{2}, \mathrm{CHCl}_{3}\right.$ to $\left.9 / 31 \mathrm{MeOH} / \mathrm{CHCl}_{3}\right)$, gave 2 (12 $\mathrm{mg}, 54 \%, 2$ steps), whose spectral data matched that reported in the literature. ${ }^{7}[\alpha]^{20} \mathrm{D}-63.5$ $\left(c\right.$ 0.2, MeOH); Lit. $^{7}[\alpha]_{\mathrm{D}}-7.9\left(c 0.18, \mathrm{CHCl}_{3}\right){ }^{43}$ IR (thin film): 3377, 2972, 2931, 2879, $1658,1649,1641,1381,1122,1061 \mathrm{~cm}^{-1}$.

\section{Supplementary Material}

Refer to Web version on PubMed Central for supplementary material.

\section{Acknowledgements}

We thank the NIH (GM 62160) for support of this work. 


\section{References}

1. Mock M, Fouet A. Annu Rev Microbiol 2001;55:647-671. [PubMed: 11544370]

2. Sylvestre P, Couture-Tosi E, Mock M. Mol Microbiol 2002;45:169-178. [PubMed: 12100557]

3. Gerhardt P. Fed Proc 1967;26:1504-1517. [PubMed: 4963765]

4. Steichen C, Chen P, Kearney JF, Turnbough CL Jr. J Bacteriol 2003;185:1903-1910. [PubMed: 12618454]

5. Daubenspeck JM, Zeng H, Chen P, Dong S, Steichen CT, Krishna NR, Pritchard DG, Turnbough CL Jr. J Biol Chem 2004;279:30945-30953. [PubMed: 15152001]

6. Mehta AS, Saile E, Zhong W, Buskas T, Carlson R, Kannenberg E, Reed Y, Quinn CP, Boons GJ. Chem Eur J 2006;12:9136-9149.

7. Werz DB, Seeberger PH. Angew Chem Int Ed 2005;44:6315-6318.

8. Adamo R, Saksena R, Kovaè P. Carbohydr Res 2005;340:2579-2582. [PubMed: 16216230]

9. Adamo R, Saksena R, Kovaè P. Helv Chim Acta 2006;89:1075-1089.

10. Saksena R, Adamo R, Kovaè P. Bioorg Med Chem Lett 2006;16:615-617. [PubMed: 16275067]

11. Guo, H.; O’Doherty, GA. 232nd ACS National Meeting; San Francisco. Sept. 10-14, 2006; Washington, DC: American Chemical Society; ORGN-917

12. According to the current recommendations for carbohydrate nomenclature the reducing end of an oligosaccharide is the downstream end. McNaught AD. Carbohydr Res 1997;297:1-92. [PubMed: 9042704]

13. Saksena R, Adamo R, Kovaè P. Carbohydr Res 2005;340:1591-1600. [PubMed: 15922317]

14. Gotoh M, Kovaè P. J Carbohydr Chem 1994;13:1193-1213.

15. Eis MJ, Ganem B. Carbohydr Res 1988;176:316-323. [PubMed: 3138026]

16. Bundle DR, Gerken M, Peters T. Carbohydr Res 1988;174:239-251. [PubMed: 2454158]

17. Liu M, Yu B, Wu X, Hui Y, Fung KP. Carbohydr Res 2000;329:745-754. [PubMed: 11125816]

18 . In the process of our investigation $\beta$-selective glycosylation by the $\alpha$-nitrilium ion method was reported. 6

19. Braccini I, Derouet C, Esnault J, du Penhoat CH, Mallet JM, Michon V, Sinay P. Carbohydr Res 1993;246:23-41.

20. Vankar YD, Vankar PS, Behrendt M, Schmidt RR. Tetrahedron 1991;47:9985-9992.

21. Codée JDC, Litjens REJN, van den Bos LJ, Overkleeft HS, van der Marel GA. Chem Soc Rev 2005;34:769-782. [PubMed: 16100617]

22. Ellervik U, Magnusson G. J Org Chem 1998;63:9314-9322.

23. Wright JA, Yu J, Spencer JB. Tetrahedron Lett 2001;42:4033-4036.

24. Xia J, Abbas SA, Locke RD, Piskorz CF, Alderfer JL, Matta KL. Tetrahedron Lett 1999;41:169-173.

25. Gaunt MJ, Yu J, Spencer JB. J Org Chem 1998;63:4172-4173.

26. David, S. Preparative Carbohydrate Chemistry. Hanessian, S., editor. Dekker; New York: 1997. p. 69-86.

27. David S, Hanessian S. Tetrahedron 1985;41:643-663.

28. Mizuno M, Cava MP, Garito AF. J Org Chem 1976;41:1485-1486.

29. Clive DLJ, Chittattu G, Wong CK. J Chem Soc, Chem Commun 1978:41-42.

30. Clive DLJ, Chittattu GJ, Farina V, Kiel WA, Menchen SM, Russell CG, Singh A, Wong CK, Curtis NJ. J Am Chem Soc 1980;102:4438-4447.

31. Heidelberg T, Martin OR. J Org Chem 2004;69:2290-2301. [PubMed: 15049621]

32. Debenham JS, Rodebaugh R, Fraser-Reid B. J Org Chem 1997;62:4591-4600.

33. Crich D, Vinogradova O. J Org Chem 2007;72:3581-3584. [PubMed: 17375956]

34. Codée JDC, van den Bos LJ, Litjens REJN, Overkleeft HS, van Boeckel CAA, van Boom JH, van der Marel GA. Tetrahedron 2004;60:1057-1064.

35. Codée JDC, Litjens REJN, den Heeten R, Overkleeft HS, van Boom JH, van der Marel GA. Org Lett 2003;5:1519-1522. [PubMed: 12713313]

36. Pozsgay V. Carbohydr Res 1979;69:284-286.

J Org Chem. Author manuscript; available in PMC 2009 January 9. 
37. Crich D, Smith M. J Am Chem Soc 2001;123:9015-9020. [PubMed: 11552809]

38. Veeneman GH, van Leeuwen SH, Zuurmond H, van Boom JH. J Carbohydr Chem 1990;9:783-796.

39. Konradsson P, Udodong UE, Fraser-Reid B. Tetrahedron Lett 1990;31:4313-4316.

40. Konradsson P, Mootoo DR, McDevitt RE, Fraser-Reid B. J Chem Soc, Chem Commun 1990:270272.

41. Wang D, Carroll GT, Turro NJ, Koberstein JT, Kovaè P, Saksena R, Adamo R, Herzenberg LA, Herzenberg LA, Steinman L. Proteomics 2007;7:180-184. [PubMed: 17205603]

42. Carpino LA, El-Faham A, Albericio F. J Org Chem 1995;60:3561-3564.

43. The literature specific rotation appears to be an error as the compound is not soluble in the recorded solvent. 


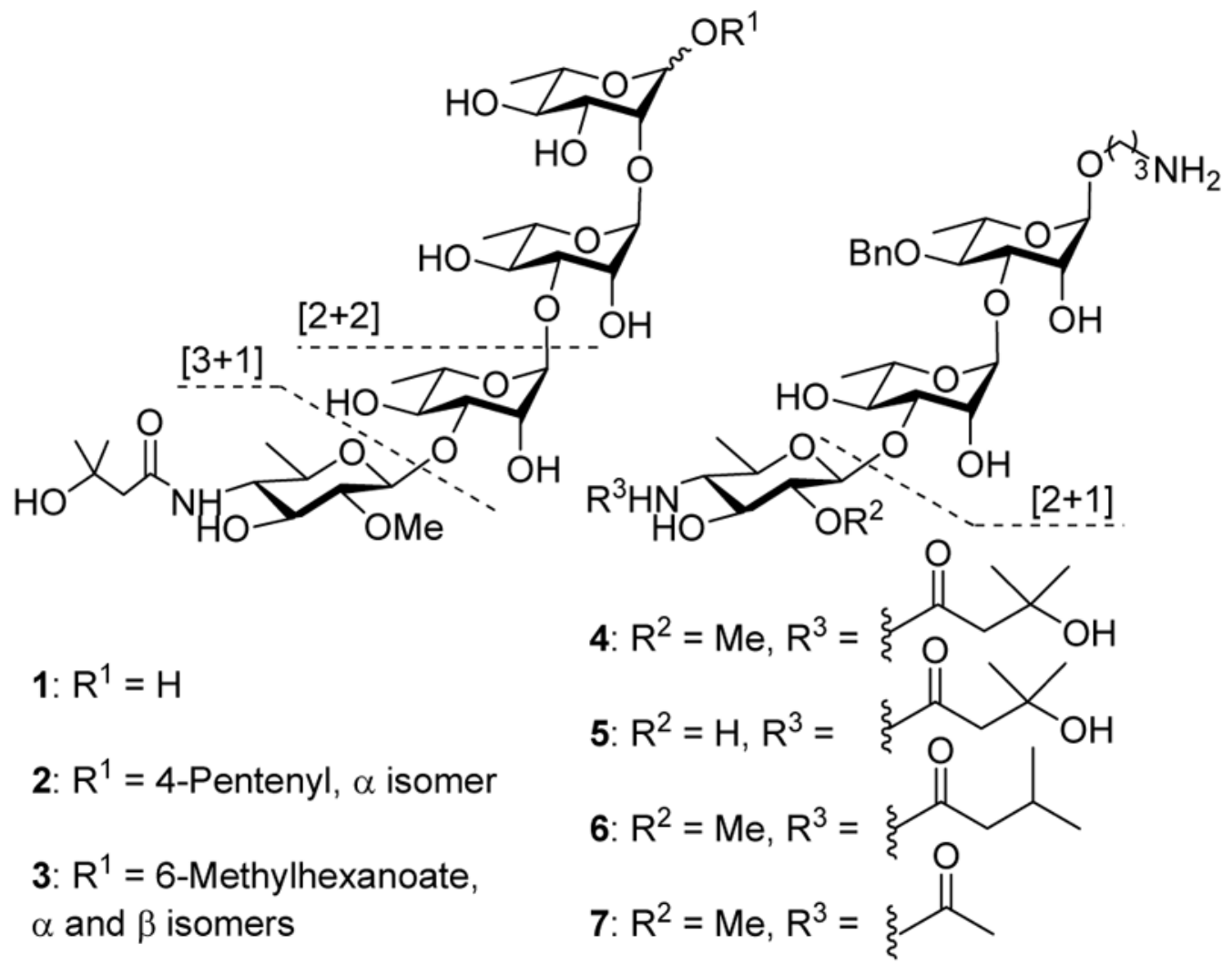

Figure 1.

Literature Approaches to the Target 


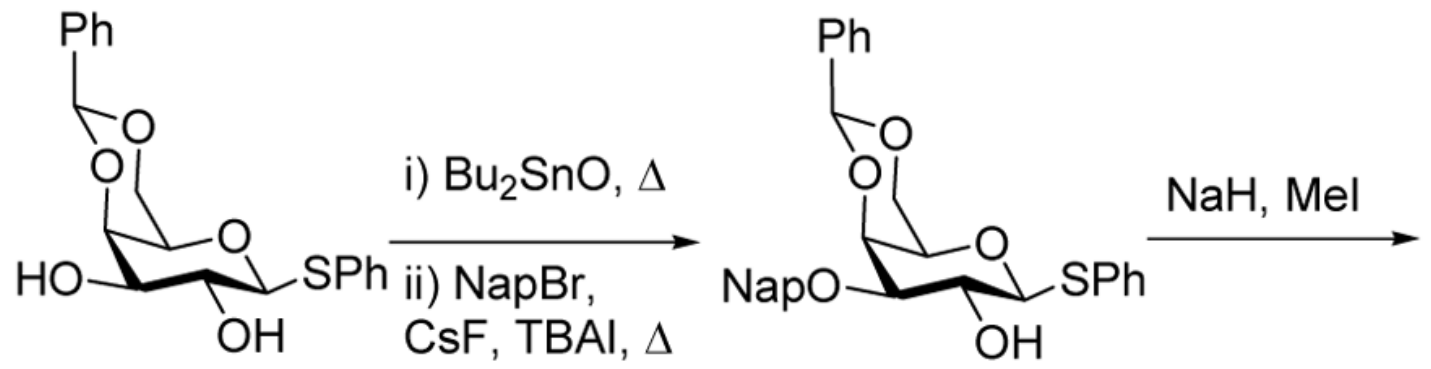

8

9, 60\% (2 steps)

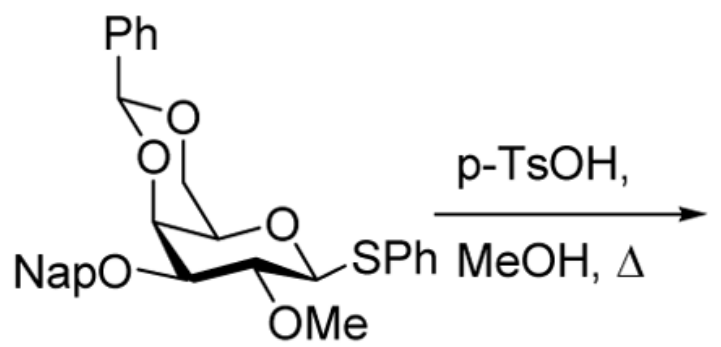

$10,80 \%$

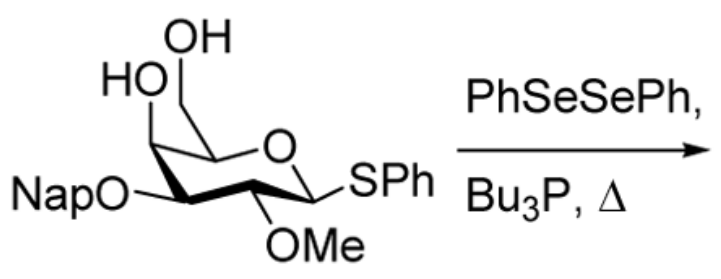

$11,95 \%$

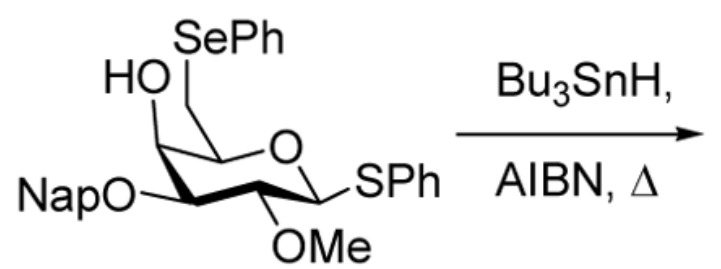

12, $77 \%$

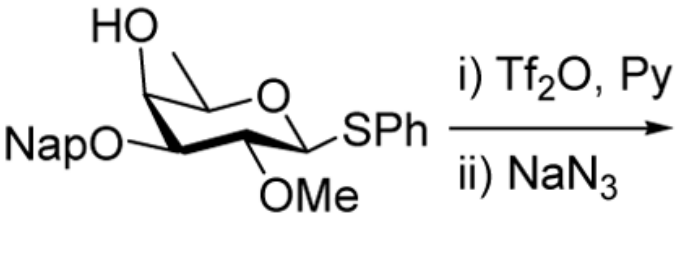

$13,85 \%$

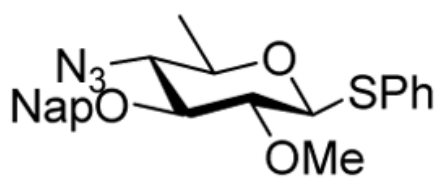

$14,87 \%$ (2 steps)

Scheme 1.

Synthesis of the Anthrose Donor 


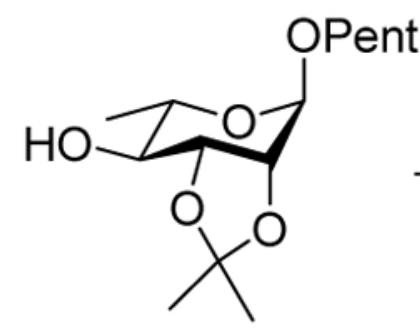

15

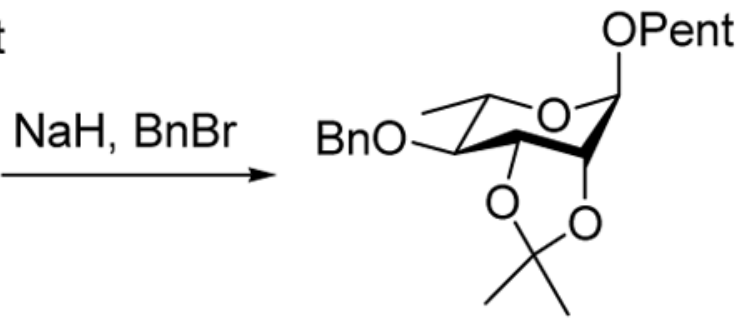

$16,90 \%$

i) $\mathrm{AcOH}, \Delta$

ii) $\mathrm{Bu}_{2} \mathrm{SnO}, \Delta$

iii) $\mathrm{BnBr}, \mathrm{CsF}$

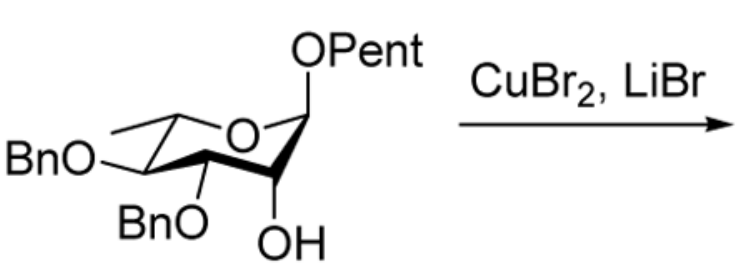

$17,74 \%$ (2 steps)

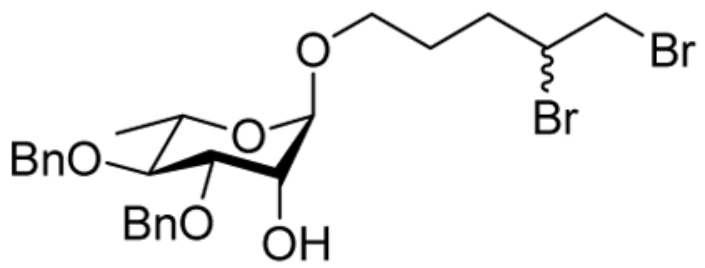

$18,89 \%$

Scheme 2.

Synthesis of Monosaccharide 18 


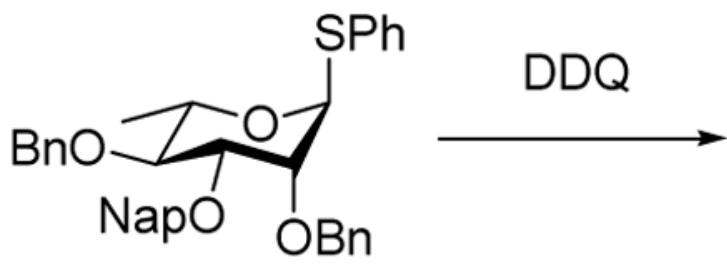

19

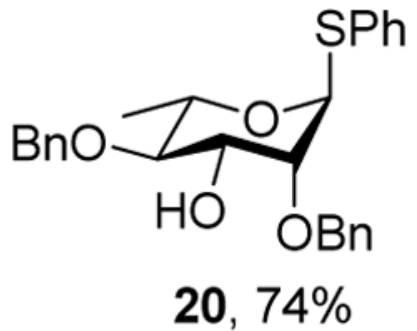

Scheme 3.

Synthesis of Monosaccharide 19 


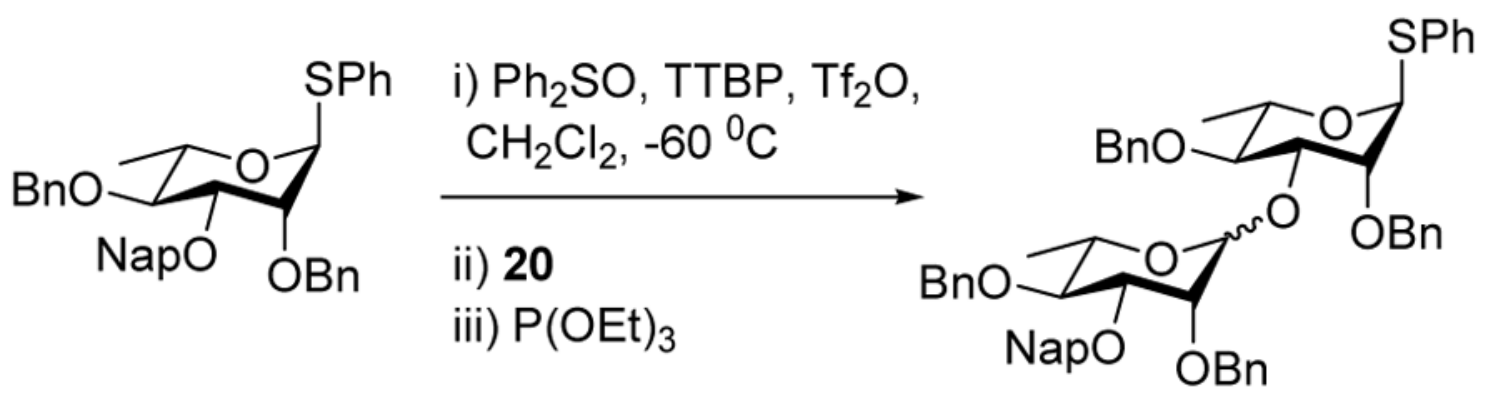

$21 \alpha, 49 \%$

$21 \beta, 7 \%$

i) $\mathrm{Ph}_{2} \mathrm{SO}$, TTBP, $\mathrm{Tf}_{2} \mathrm{O}$,
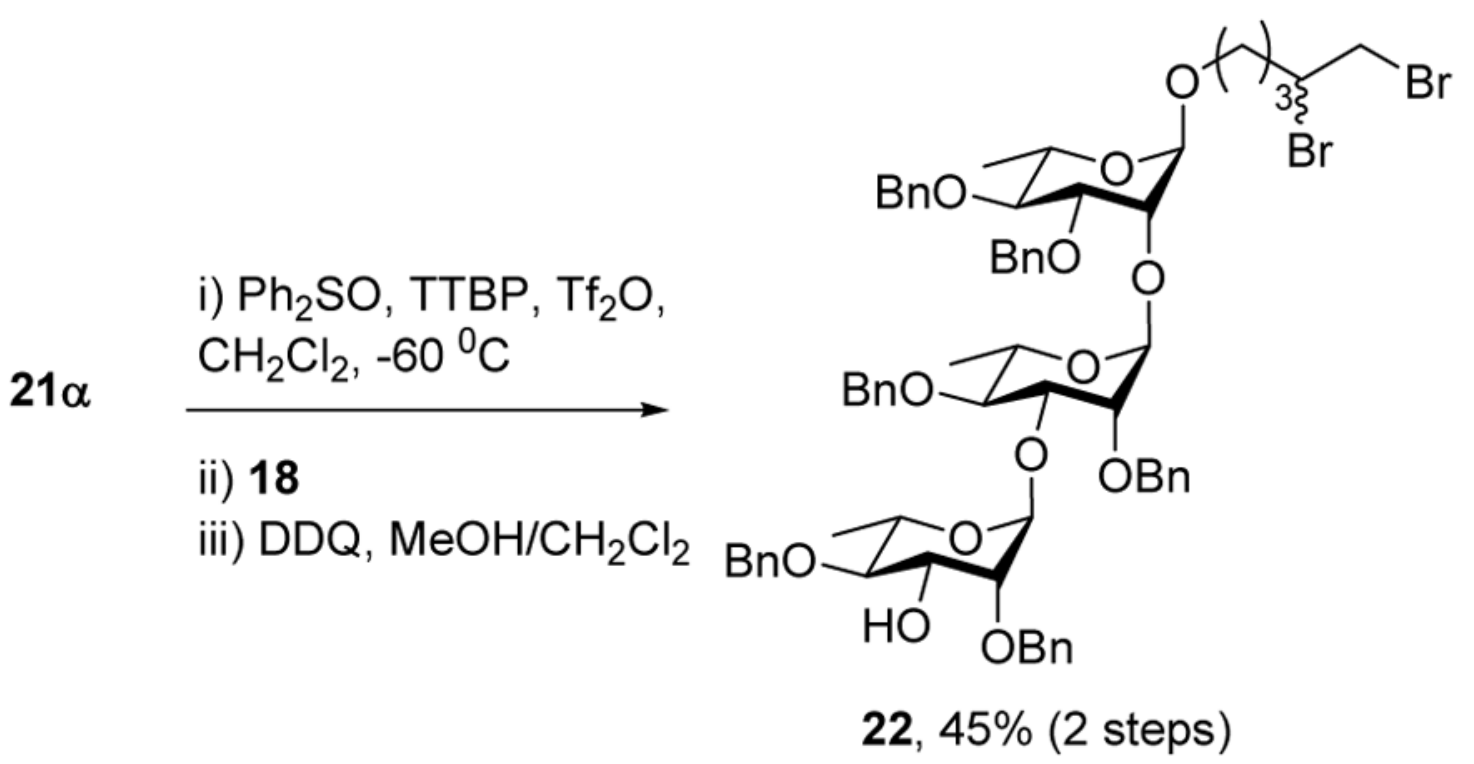

Scheme 4.

Trisaccharide Synthesis 
<smiles>O=S(c1ccccc1)N1CCCCC1</smiles>

BSP<smiles>CC(C)(C)c1cc(C(C)(C)C)nc(C(C)(C)C)n1</smiles>

TTBP<smiles>O=C1CCC(=O)N1I</smiles>

NIS

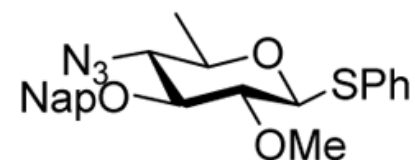<smiles>CO[C@H]1O[C@H](O)[C@H](O)[C@H](O)[C@H]1O</smiles>

23

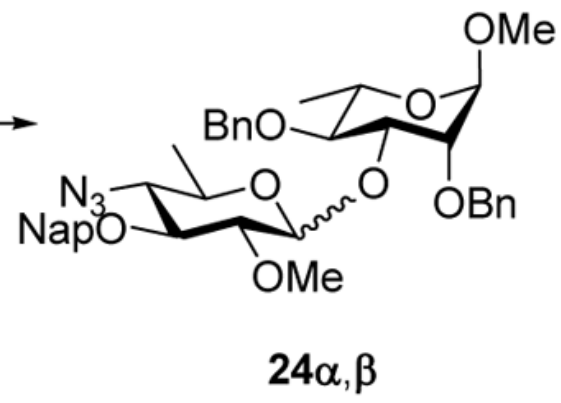

\section{Promoter \\ Solvent \\ $\alpha / \beta$ ratio, (yield)}

$\mathrm{BSP} / \mathrm{TTBP} / \mathrm{Tf}_{2} \mathrm{O} \quad \mathrm{CH}_{2} \mathrm{Cl}_{2} \quad 7.3 / 1(82 \%)$

$\mathrm{BSP} / \mathrm{TTBP} / \mathrm{Tf}_{2} \mathrm{O}$

$\mathrm{C}_{2} \mathrm{H}_{5} \mathrm{CN} \sim 1 / 1(70 \%)$

NIS/TfOH

$\mathrm{C}_{2} \mathrm{H}_{5} \mathrm{CN} \quad 1 / 3.3(93 \%)$

Scheme 5.

Exploratory Couplings to the Anthrose Donor 


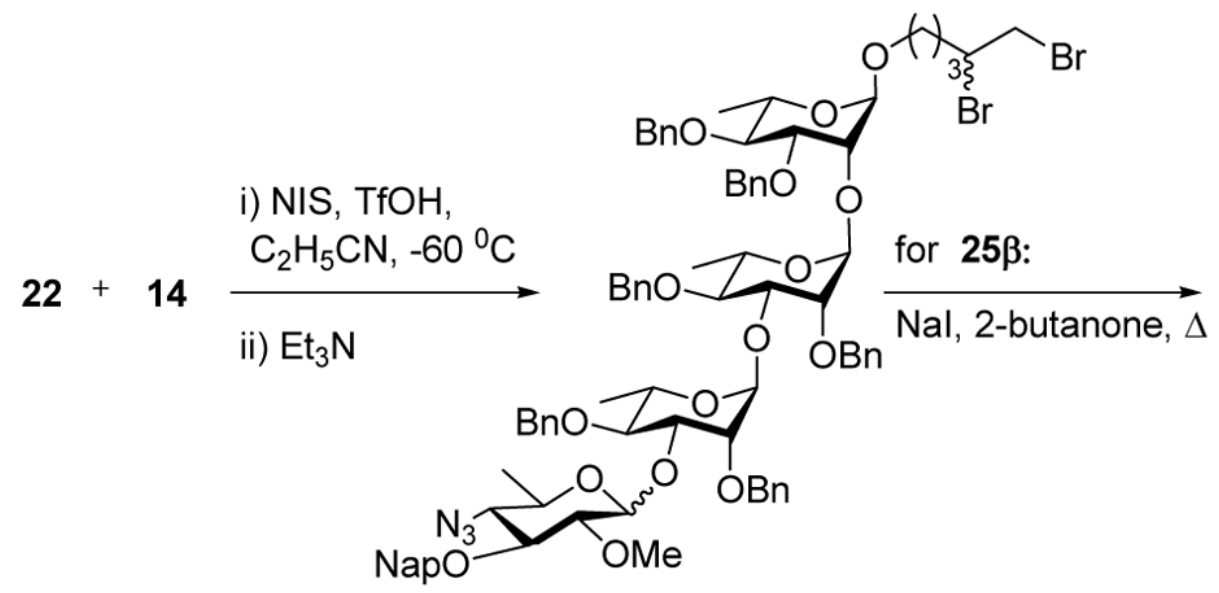

$25 \alpha, 21 \%$

25及, $71 \%$

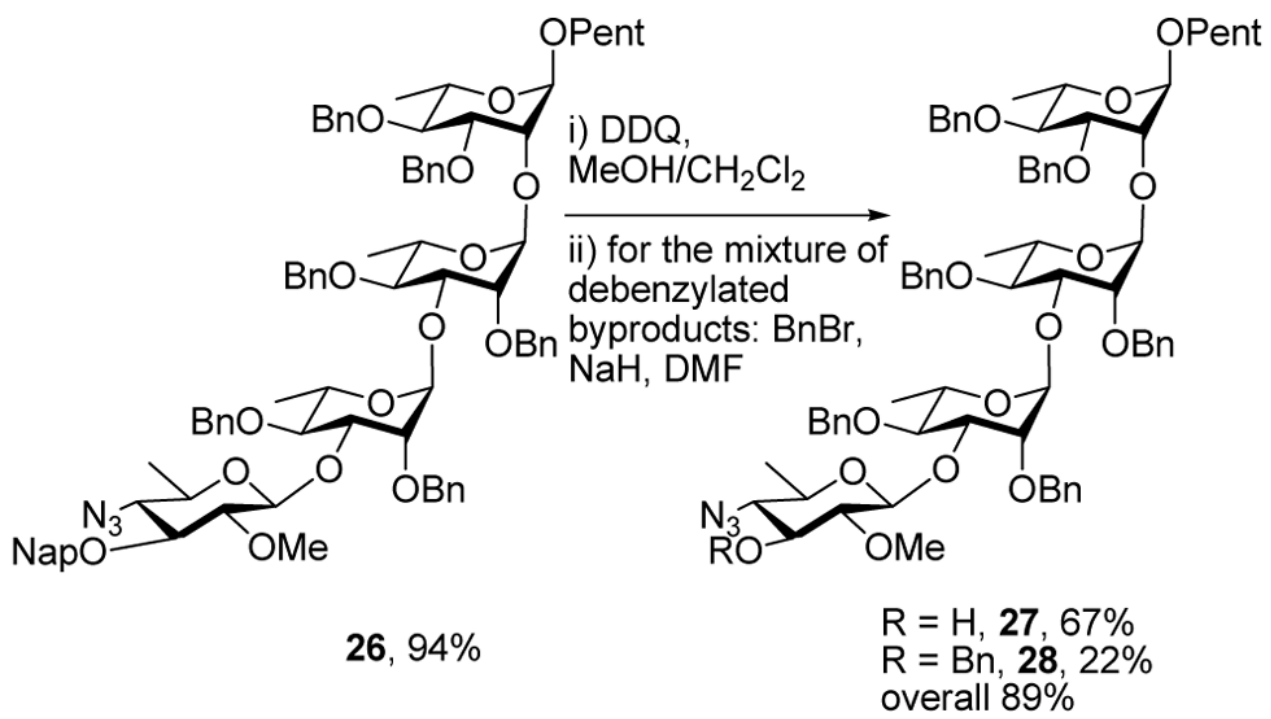

i) $\mathrm{Na}, \mathrm{NH}_{3}, \mathrm{THF},-78{ }^{\circ} \mathrm{C}$

ii) 3-hydroxy-3-methylbutyric acid,
HATU, (i-Pr) $)_{2}$ EtN, DMF

Scheme 6.

Completion of the Synthesis 